\title{
How Do Industries and Firms Respond to Changes in Local Labor Supply?
}

\author{
Christian Dustmann, University College London
}

Albrecht Glitz, Universitat Pompeu Fabra and Barcelona GSE

This paper analyzes how changes in the skill mix of local labor supply are absorbed by the economy, distinguishing between three adjustment mechanisms: wages, expansion in size of those production units using the more abundant skill group more intensively, and more intensive use of the more abundant skill group within production units. We contribute to the literature by analyzing these adjustments on the firm rather than industry level, using German administrative data. We show that most adjustments occur within firms through changes in relative factor intensities and that firms entering and exiting the market are an important additional absorption mechanism.

\section{Introduction}

Labor economists typically assume that local economies primarily absorb changes in local labor supply through changes in wages, and a large

We thank the editor, Paul Beaudry, David Green, Ethan Lewis, Francesc Ortega, Ian Preston, Jan Stuhler, and seminar participants at UPF and the Outsourcing and Migration Conference in Turin for comments. We are grateful to Johannes Ludsteck and Marco Hafner from the Institute for Employment Research for invaluable support with the data. We also thank the Barcelona GSE Research Network, the Government of Catalonia, the Spanish Ministry of Science (Project Nos. ECO200806395-C05-01 and ECO2011-30323-C03-02), and the Norface Programme on Migration for their support. Information concerning access to the data used in this

[Journal of Labor Economics, 2015, vol. 33, no. 3, pt. 1]

(C) 2015 by The University of Chicago. All rights reserved. 0734-306X/2015/3303-0005\$10.00

Submitted August 8, 2012; Accepted January 7, 2014; Electronically published June 29, 2015 
and growing body of literature focuses on the magnitude of these changes. ${ }^{1}$ Traditional open economy models, in contrast, emphasize adjustments to labor supply shocks through changes in the output mix produced by the local economy (see Rybczynski 1955). More recently, shifts toward production technologies that are more intensive in the use of the relatively more abundant labor type have been put forward as a third potential adjustment mechanism. Such technology shifts are thought of as being either due to profit-maximizing innovators' endogenous choice of research direction (see, e.g., Acemoglu 1998, 2002) or producers' selection of an optimal production technology from a given pool of alternatives (see, e.g., Beaudry and Green 2003, 2005; and Caselli and Coleman 2006). Existing studies that evaluate the relative magnitude of the latter two channels using industry-level data identify technology adjustments as the more important of the two (see, e.g., Hanson and Slaughter 2002; Lewis 2003; Gandal, Hanson, and Slaughter 2004; Card and Lewis 2007; and González and Ortega 2011). ${ }^{2}$ These studies argue that open economy adjustments should induce more growth in industries that make more intensive use of the relatively more abundant type of labor (often referred to as "between" changes), whereas technology adjustments should lead to within-industry changes in the relative employment of the more abundant labor type (referred to as "within" changes).

Being conducted on the industry level, however, one problem with the existing studies is that, if firms within an industry produce heterogeneous products, changes in aggregate industry-level factor intensities that are the result of size adjustments between firms operating within that same industry may be incorrectly attributed to technology-induced factor intensity adjustments. With the trade literature providing extensive evidence of product heterogeneity even within narrowly defined industries or product categories (see, e.g., Schott [2004] or Broda and Weinstein [2006]), such aggregation error could be sizable. ${ }^{3}$

article is available as supplementary material online in a zip file. Contact the corresponding author, Albrecht Glitz, at albrecht.glitz@upf.edu.

${ }^{1}$ See, e.g., Card (2001), Borjas (2003), Dustmann, Fabbri, and Preston (2005), Glitz (2012), Manacorda, Manning and Wadsworth (2012), Ottaviano and Peri (2012), or Dustmann, Frattini, and Preston (2013).

2 These conclusions are supported by research evidence that focuses more directly on the endogenous adoption of technology, showing that automation machinery indeed expands more rapidly in those areas in which the relative supply of skilled labor grows fastest (Lewis 2011) and that skill abundance leads to a faster adoption of new technologies (Beaudry, Doms, and Lewis 2010).

${ }^{3}$ On the other hand, if all firms in the same industry produced the same product but chose different coexisting technologies, as in Beaudry and Green (2003, 2005), the between-firm within-industry changes would simply reflect differential growth of firms that produce the same product within an industry. We will discuss this possibility below. 
The first contribution of this paper is therefore to assess whether aggregation to the level of industries leads indeed to an overstatement of the extent of technology adjustments to labor supply changes. To achieve that, we use comprehensive firm-level data from administrative sources, which allow us to assess and quantify the channels through which immigrationinduced local labor supply shocks are absorbed into the economy at different levels of aggregation.

Our second contribution is to isolate and quantify the role of firm creation and destruction for the absorption of labor supply changes. Given the high turnover of firms and new firms' lower adjustment costs, not accounting for this mechanism could be an important omission. ${ }^{4}$ Unlike other studies that rely on survey information, our administrative data encompass the entire universe of firms, including small ones. This is particularly important if some of the adjustments to local labor supply shocks do indeed take place through the (net) creation of new firms, as it is likely that small firms play a particularly important role in this process. ${ }^{5}$

While adjustments in production technologies lead to changes in relative factor intensities within production units, the same is true for changes in relative wages. In terms of a standard model of production, the first interpretation refers to a change in relative inputs due to a technologyinduced rotation of the isoquant around a fixed isocost line, while the second interpretation refers to a change in relative inputs due to an isocost line that rotates around a fixed isoquant. Thus, in order to assess whether the observed within-firm changes in relative inputs are indeed due to technology adjustments, we estimate the possible effects of local labor supply shocks on relative wages, differing from existing work by distinguishing between the impact in the tradable sector and the nontradable sector.

To perform our analysis, we draw on an administrative data source that covers the entire West German workforce from 1985 to 1995. The data provide not only basic worker characteristics, including educational levels, but also identifiers for the employing firms and information on their industry affiliation. We can thus accurately compute the skill mix employed in each firm. ${ }^{6}$ Regional identifiers further allow us to identify local labor markets. We focus on the period 1985-95 since it was characterized

${ }^{4}$ In our sample and over the period we analyze, firm turnover is about $41 \%$, a figure in line with findings for the United States. For example, Dunne, Roberts, and Samuelson (1989a, 1989b) find that 40\% of firms in manufacturing in the United States disappear over a 5-year period and are replaced by new entrants.

${ }^{5}$ For instance, Bernard and Jensen (1997) compare between and within shifts in employment on the industry level with those calculated from a sample of manufacturing plants. However, using data from the US Annual Survey of Manufactures (ASM), their firm sample is restricted to large manufacturing firms that survived throughout their sampling periods (1973-79 and 1979-87).

${ }^{6}$ Rather than referring to firms in the legally defined sense, our data refer to business establishments or plants, which we believe is the appropriate unit for the purposes of our analysis. For simplicity, we refer to these as "firms." 
by large immigrant inflows, which we can exploit to isolate the absorption mechanisms that respond to exogenous supply shocks. ${ }^{7}$

The results from our main decomposition on the firm level support previous work on the industry level (e.g., Lewis 2003; Card and Lewis 2007; González and Ortega 2011) in showing that, in the tradable sector, withinfirm changes in factor intensity are more important in accommodating changes in local labor supply than changes in output mix. Since we do not find that labor supply shocks affect relative wages, these within adjustments are most likely due to changes in technology. To give an example, based on our instrumental variable regressions, adjustments through withinfirm changes in factor intensities explain around $71 \%$ of the overall adjustment to immigration-induced labor supply shocks in the tradable sector, while adjustments through changes in the output mix explain only $14 \%$. Our findings further show that the role of new and exiting firms in absorbing labor supply shocks is important, and with a contribution of around $15 \%$, it is similar in magnitude to the estimated contribution through output mix adjustments. Finally, comparing results at different levels of aggregation shows that a standard industry-level analysis is likely to overestimate the effect commonly assigned to technology adjustments: when the level of aggregation is reduced stepwise from two-digit industries to threedigit industries and then to the firm level, the output mix changes become relatively more important.

The structure of the paper is as follows. In the next section, we explain our analytical framework. In Section III, we describe the data and provide some descriptive evidence on the industry and firm structure in West Germany between 1985 and 1995. In Section IV, we present our empirical results. We first show the extent to which local relative wages have responded to changes in local factor supplies and then present the main firm-level estimates of the relative contribution of output and technology adjustments to the absorption of local labor supply shocks. We discuss the specific role of new and old firms in this process and relate the firm-level results to those that would be obtained by an industry-level analysis. Finally, we provide some additional results on the role of firm size and nationwide changes in industry-specific production technologies. Section V concludes.

\section{Analytical Framework}

Our starting point to analyze the different adjustment mechanisms to changes in local labor supply is a well-known accounting identity that de-

${ }^{7}$ As an alternative to immigration-induced shocks to local labor supply, Ciccone and Peri (2011) exploit changes in compulsory schooling legislation and child labor laws across US states over the period 1950-90 to study the different mechanisms through which local industry-level production structures adjust to changes in labor supply. 
composes the change in a region $r^{\prime}$ s supply of labor type $i, \Delta X_{i r}$, relative to labor supply in the base period, $X_{\text {iro }}$, into a component that accounts for changes in the output mix produced by local production units and a component that accounts for changes in relative factor intensities used in the production of each output good (compare Lewis 2003; Card and Lewis 2007; and González and Ortega 2011). Assuming that factor supplies $X_{\text {ir }}$ in each region are equal to factor demands $N_{i r}$ and abstracting, for now, from possible adjustments through nonemployment, this identity is given by (dropping region subscripts for simplicity):

$$
\begin{aligned}
\frac{\Delta X_{i}}{X_{i_{0}}} & =y_{i}=\sum_{j=1}^{J} s_{i j 0} \% \Delta M_{j}+\sum_{j=1}^{J} s_{i j} \% \Delta\left(\frac{N_{i j}}{M_{j}}\right)+R_{i} \\
& =x_{1 i}+x_{2 i}+R_{i},
\end{aligned}
$$

where $M_{j}$ is total employment in production unit $j, N_{i j}$ is the number of employees of skill group $i$ in production unit $j, s_{i j_{0}}=N_{i j_{0}} / X_{i_{0}}$ is the share of workers in skill group $i$ that is employed in production unit $j$ in the base period, $\% \Delta$ indicates the percentage change in the respective variable between two periods, and $R_{i}$ is a residual term that cannot be uniquely assigned to either of the first two components. ${ }^{8}$ For details of this derivation, see Appendix B, Section B1.

Since equation (1) is an identity, the fraction of the change in factor supplies that can be attributed to each of its constituent components can be readily computed. To provide an economic interpretation for these fractions, assume that each production unit produces a tradable output good whose price is set on international markets using a simple constant elasticity of substitution (CES) production function with only two input factors, skilled and unskilled labor, so that $Y^{j}\left(N_{1}, N_{2}\right)=\left[\alpha_{j} N_{1}^{\rho}+\left(1-\alpha_{j}\right) N_{2}^{\rho}\right]^{1 / \rho}$. 9 Suppose first that production technologies $\left(\alpha_{j}\right)$ are fixed. In this case, the unit value isoquants for the output of each production unit are also fixed, and they determine, in equilibrium, relative wages and the factor intensities with which each production unit produces its output (see, e.g., Gaston and Nelson 2000). Now assume a particular region experiences a labor supply shock of labor type $i^{\prime}$. Since unit value isoquants are fixed, so are equilibrium wages (the Factor Price Insensitivity Theorem; see Leamer and Levinsohn 1995), which in turn implies fixed factor intensities $\left(\% \Delta\left(N_{i j} / M_{j}\right)=0\right.$

${ }^{8}$ This residual term, given by $R_{i}=\sum_{j=1}^{J} s_{i j_{0}} \% \Delta M_{j} \times \% \Delta\left(N_{i j} / M_{j}\right)$, is often implicitly assigned in equal shares to the scale and intensity effects by evaluating the corresponding changes at the mean of the first and last period considered (see, e.g., Autor, Katz, and Krueger 1998; Hanson and Slaughter 2002).

${ }^{9}$ The corresponding unit cost functions are given by

$$
C^{j}\left(w_{1}, w_{2}\right)=\left[\alpha_{j}^{\sigma} w_{1}^{(1-\sigma)}+\left(1-\alpha_{j}\right)^{\sigma} w_{2}^{(1-\sigma)}\right]^{1 / 1-\sigma},
$$

where $\sigma$ is the elasticity of substitution between skilled and unskilled workers. 
for all $i$ and $j) .{ }^{10}$ In this setting, all adjustment to a labor supply shock takes place through changes in the local output mix, with those production units increasing in scale that are more intensive in the use of the now more abundant labor input. The first term in equation (1) captures this particular adjustment channel, with relative changes in overall employment $\left(\% \Delta M_{j}\right)$ corresponding to relative changes in output $\left(\% \Delta Y_{j}\right)$ under constant returns to scale. This is the channel many open economy models and, specifically, the Rybczynski Theorem (see Rybczynski 1955), propose as the main adjustment mechanism to labor supply shocks.

However, if factor price insensitivity does not hold and/or if the technology is not fixed, then a supply shock of a particular factor $i^{\prime}$ can also lead to changes in the fraction of that factor used in production, either through its effect on relative wages or by inducing technological change. For our simple CES production function, the term referring to changes in relative factor intensities in equation (1) can be expressed as (for a change in skill group 1):

$$
\% \Delta\left(\frac{N_{1 j}}{M_{j}}\right) \cong d \ln \left(\frac{N_{1 j}}{M_{j}}\right)=B\left[\left(\frac{d w_{2}}{w_{2}}-\frac{d w_{1}}{w_{1}}\right)+\left(\frac{1}{1-\alpha_{j}}\right) \frac{d \alpha_{j}}{\alpha_{j}}\right],
$$

where $B=\sigma\left(1-\alpha_{j} / w_{2}\right)^{\sigma} /\left[\left(\alpha_{j} / w_{1}\right)^{\sigma}+\left(\left(1-\alpha_{j}\right) / w_{2}\right)^{\sigma}\right]$. Relative changes in factor shares within a production unit are thus driven by either changes in relative wages (corresponding to the linear isocost line rotating around the isoquant) or changes in production technology (corresponding to the isoquant rotating around the isocost line), where the latter reflect adjustments that lead to a more intensive use of the more abundant factor and which we assume here to arise in the form of factor-biased technical change. The second term in equation (1) thus captures the contribution of both wage- and technology-induced changes in relative factor intensities within production units to the absorption of changes in local labor supply. Since its economic interpretation depends crucially on the relative importance of the two channels, we will, in a first step, analyze the evidence for relative wage adjustments in response to changes in local labor supply. If we can rule out a significant role for wage adjustments, the contribution of the second term of equation (1) can be interpreted as evidence for technology adjustments. ${ }^{11}$

10 The Factor Price Insensitivity Theorem holds as long as there are at least as many tradable goods as factors of production (see, e.g., Ethier [1984] for details) and can be extended to account for the existence of nontradable goods (see Komiya 1967; Ethier 1972).

${ }^{11}$ We thus interpret changes in relative factor intensities when relative wages remain unchanged as changes in production technology. For example, suppose a typical midsize firm in Germany employs both highly trained engineers and manual workers to produce a specific car component. If there is an inflow of engineers into the market and the firm now adjusts its workforce and uses relatively more 


\section{A. Empirical Implementation: Wages}

To assess to what extent labor supply changes lead to adjustments in local relative wages, we estimate the following model:

$$
\Delta \log w_{i r}=\delta_{r}+\eta_{i}+\gamma \% \Delta X_{i r}+\varepsilon_{i r},
$$

where $\Delta \log w_{i r}$ is the percentage change in gross daily median wages, $\% \Delta X_{i r}$ is the percentage growth of the labor force with education level $i$ in region $r$, and $\delta_{r}$ and $\eta_{i}$ are full sets of region and skill group fixed effects that account for changes in overall regional wage levels and national trends in skill-specific wages, respectively. Notice that equation (2) corresponds to a level specification where we allow for region- and skill-specific effects as well as their changes over time. ${ }^{12}$

As is well known, the above estimation equation suffers from an endogeneity problem, since unobserved skill-specific local demand shocks are likely to attract suitably skilled workers into the local labor force. As a result, OLS estimates of equation (2) tend to yield attenuated estimates of $\gamma$, understating the true effect exogenous labor supply shocks have on relative wages. To deal with this issue, we follow the standard approach in the literature and use predictions of international immigrant inflows into a region based on historical settlement patterns to instrument the relative changes in local skill-specific labor supply (see, e.g., Card 2001). The idea is that immigrants tend to settle in areas in which other immigrants of the same country of origin have already settled earlier (Bartel 1989; Jaeger 2007) but that these historical settlement patterns are not related to current demand-induced changes in local labor supply. We define $\Delta I_{c}$ as the

engineers to produce the same product, and if relative wages between engineers and manual workers remain unchanged, then we interpret this as a change in the underlying production technology. In this particular example, firms may have to complement their new engineers with additional technology, such as automated production systems, and/or change the organizational structure of production.

${ }^{12}$ Equation (2) is derived from a standard production function that uses capital and labor in each region to produce an aggregate output good, $Y_{r t}=F\left(K_{r t}, L_{r t}\right)$, where the labor input is itself a CES aggregate of three different skill groups,

$$
L_{r t}=\left(\sum_{i=1}^{3} \alpha_{i r t}\left(X_{i r t}\right)^{\frac{\sigma-1}{\sigma}}\right)^{\sigma / \sigma-1},
$$

and the $\alpha_{i r t}$ determine the relative productivity of labor input $i$ in region $r$ at time $t$. Equating the marginal product of each skill group with its wage rate and allowing the productivity terms to vary by skill group, region, and time period so that $\log \alpha_{i r t}=\alpha_{i r}+\alpha_{r t}+\alpha_{i t}+\alpha_{i r t}^{\prime}$ gives, after first differencing over time, $\Delta \log w_{i r t}=$ $\Delta \log F_{L}\left(K_{r t}, L_{r t}\right) L_{r t}^{1 / \sigma}+\Delta \alpha_{r t}+\Delta \alpha_{i t}-(1 / \sigma) \Delta \log X_{i r t}+\Delta \alpha_{i r t}^{\prime}$. This expression is the basis for eq. (2), where the first two terms on the right-hand side are absorbed by the region fixed effects $\delta_{r}$ and the third term by the skill group fixed effects $\eta_{i}$. See also Card (2001), Lewis (2003), or González and Ortega (2011). 
net overall number of immigrants with nationality $c$ entering Germany during the period $1985-95, \lambda_{c r}$ as the share of all immigrants of nationality $c$ in Germany who reside in labor market $r$ in some initial period, and $\theta_{c i}$ as the nationwide fraction of newly arriving immigrants of nationality $c$ that fall into skill group $i$. If new immigrants distribute themselves across the country according to the existing distribution of previous immigrants from their home country, then $\lambda_{c r} \times \theta_{c i} \times \Delta I_{c}$ gives the number of new immigrants of nationality $c$ with skill $i$ that are expected to settle in region $r{ }^{13}$ Summing over origin countries and dividing by the overall skill-specific labor force in region $r$ at the beginning of the observation window in 1985 results in an estimate of the expected overall skill-specific immigrant inflow rate into local labor market $r$ :

$$
z_{i r}=\frac{\sum_{c} \lambda_{c r} \theta_{c i} \Delta I_{c}}{X_{i r_{0}}} .
$$

To compute the $\lambda_{c r}$, we use the existing regional distributions of immigrants across Germany in 1975, the earliest year available in our administrative data base. Under the plausible assumption that current regional demandinduced labor market shocks are uncorrelated with past immigrant settlement patterns, this instrument leads to estimates that have a causal interpretation. In Appendix A, we describe the composition of the immigrant population in Germany and the changes in composition and skill structure over the decade under study in more detail.

\section{B. Empirical Implementation: Adjustments through Output Mix and Technology}

After assessing the role of relative wage adjustments, we then return to our accounting identity. To obtain summary measures of the relative contribution of adjustments in scale and intensity to the absorption of changes in local labor supply, we regress each of the components on the right-hand side of equation (1) on the percentage change in skill-specific labor supply in a region, $\Delta X_{i r} / X_{i r_{0}}=y_{i r}$. This results in regression equations $x_{1 i r}=a_{1}+$ $b_{1} y_{i r}+\varepsilon_{i r}^{\text {scale }}, x_{2 i r}=a_{2}+b_{2} y_{i r}+\varepsilon_{i r}^{\text {intensity }}$, and $R_{i r}=a_{3}+b_{3} y_{i r}+\varepsilon_{i r}^{\text {residual }}$. Due to the underlying identity $y_{i r}=x_{1 i r}+x_{2 i r}+R_{i r}$, the OLS regression coefficients for each of the single terms must sum up to one and thus measure the average relative contribution of the corresponding component to the absorption of changes in labor supply on the local level. ${ }^{14}$

${ }^{13}$ In contrast to previous studies that have used the overall lagged immigrant concentration as an instrument for current changes (e.g., Altonji and Card 1991; Dustmann et al. 2005), we distinguish between 15 nationality-specific immigrant distributions (see table A1) when constructing our instrumental variable.

${ }^{14}$ The OLS estimates for $b_{1}, b_{2}$, and $b_{3}$ are given by $\hat{b}_{1}=\operatorname{Cov}\left(y, x_{1}\right) / \operatorname{Var}(y)$, $\widehat{b}_{2}=\operatorname{Cov}\left(y, x_{2}\right) / \operatorname{Var}(y)$ and $\hat{b}_{3}=\operatorname{Cov}(y, R) / \operatorname{Var}(y)$. Since $\operatorname{Var}(y)=\operatorname{Var}\left(x_{1}\right)+$ $\operatorname{Var}\left(x_{2}\right)+\operatorname{Var}(R)+2 \operatorname{Cov}\left(x_{1}, x_{2}\right)+2 \operatorname{Cov}\left(x_{1}, R\right)+2 \operatorname{Cov}\left(x_{2}, R\right), \widehat{b}_{1}+\widehat{b}_{2}+\widehat{b}_{3}=1$. 
In interpreting the OLS parameter estimates, we first recognize that a positive estimate of, for instance, $b_{1}$ may indicate that an increase in the labor supply of, for example, low-skilled workers increases the scale of production units in affected regions that use low-skilled workers more intensively. It may equally indicate, however, that low-skilled workers move to regions in which firms that use their skill type more intensively are expanding in size. For example, the construction of a large infrastructure project in a specific local area may require low-skill intensive construction companies to hire more workers, implying that results from straightforward OLS regressions have no causal interpretation. Reversely, endogeneity may also arise due to shocks to local technology. Thus, the estimates identified by OLS measure how relative changes in the availability of different labor types are absorbed through changes in the output mix produced by local production units and by changes in relative factor intensities used by each production unit in the production of its output good. These are interesting parameters in that they describe the importance of the two adjustment channels when moving from one equilibrium in the local labor market to another. However, they do not answer the question of how exogenous labor supply shocks that change the skill composition of local labor markets are absorbed by the local economy.

To identify adjustment to such exogenous shocks, we apply our IV strategy based on immigration-induced labor supply shocks (denoted by $z_{i r}$ ). If $\operatorname{Cov}\left(\varepsilon_{i r}^{\text {scale }}, z_{i r}\right)=\operatorname{Cov}\left(\varepsilon_{i r}^{\text {intensity }}, z_{i r}\right)=\operatorname{Cov}\left(\varepsilon_{i r}^{\text {residual }}, z_{i r}\right)=0$ and $\operatorname{Cov}\left(y_{i r}\right.$, $\left.Z_{i r}\right) \neq 0$, the IV estimator identifies the effect of exogenous changes in local labor supply on scale and intensity adjustments of local production units. As before, the IV estimates will sum up to one and can thus be interpreted as the relative contribution of the specific adjustment channel to the absorption of labor supply shocks. ${ }^{15}$ Note that IV and OLS estimates are not directly comparable: while the OLS estimates identify the share of the overall change in relative labor supply in a region that is absorbed by a particular channel, the IV estimates identify the share of an immigrationinduced labor supply shock that is absorbed by a particular channel. ${ }^{16}$

Following the literature, we focus our analysis on the tradable sector since the output mix adjustment channel is predicated on fixed output prices (compare Hanson and Slaughter 2002; González and Ortega 2011). As a robustness check, in some specifications we further restrict the trad-

${ }^{15}$ Denote the IV estimates for $b_{1}, b_{2}$ and $b_{3}$ by $\tilde{b}_{1}=\operatorname{Cov}\left(x_{1}, z\right) / \operatorname{Cov}(y, z)$, $\tilde{b}_{2}=\operatorname{Cov}\left(x_{2}, z\right) / \operatorname{Cov}(y, z)$, and $\tilde{b}_{3}=\operatorname{Cov}\left(x_{3}, z\right) / \operatorname{Cov}(y, z)$. Since $\operatorname{Cov}(y, z)=$ $\operatorname{Cov}\left(x_{1}, z\right)+\operatorname{Cov}\left(x_{1}, \operatorname{Cov} z\right)+\operatorname{Cov}\left(x_{3}, z\right)$, the IV estimates sum up to one.

${ }^{16}$ If, e.g., technology changes will only be induced by exogenous labor supply shifts, but scale adjustments are due to demand-induced changes in local labor supply, then the same variation will identify the technology coefficient in both OLS and IV. However, as the scale effect will be zero in the IV regression, the estimated coefficient for the technology adjustment will be larger due to the addingup property. 
able sector to production units in manufacturing since their production of tradable outputs is unambiguous. To construct a measure of the overall employment change that is absorbed by the tradable sector, we first subtract from the actual observed change in skill-specific local labor supply that part that is absorbed by the nontradable sector. When focusing on the manufacturing sector only, we also subtract the employment absorbed by those tradable sectors that are not manufacturing sectors. In addition, we need to take account of unemployment in the empirical implementation. Specifically, because our focus is on adjustments in the employment structure across and within production units, we subtract the part of the observed change in labor supply that is absorbed through unemployed individuals. The change in skill-specific employment in the tradable sector is then given by $\Delta N_{i}=\Delta X_{i}-\Delta N_{i}^{\mathrm{NT}}-\Delta U_{i}$, where $\Delta N_{i}$ is the change in employment of skill group $i$ over our observation period, and $\Delta X_{i}, \Delta N_{i}^{\mathrm{NT}}$, and $\Delta U_{i}$ are the changes in overall labor supply, employment in the nontradable sector, and unemployment of skill group $i$, respectively. ${ }^{17}$

\section{Firm-Level Analysis}

As our analysis will be on the level of the firm rather than industry, we need to extend the decomposition in equation (1) by allowing for the creation of new firms (i.e., firms that we observe in 1995 but that did not exist in 1985) and the exit of old firms (i.e., firms that we observe in 1985 but that do not exist any more in 1995) as an additional adjustment channel to local labor supply changes.

Accounting for entering and exiting firms (the sum of which we refer to as "net new firms"), and denoting those firms that existed in both 1985 and 1995 as "permanent" firms, the change in skill-specific employment in all firms in the tradable sectors $j$ in a local labor market can be written as

$$
\begin{cases}\frac{\Delta N_{i}}{N_{i_{0}}}=\% \Delta N_{i}= \\ \begin{cases}\sum_{j} \sum_{f \in X_{j}^{p}} s_{i j f^{\prime}} \% \Delta M_{i f} & \text { permanent firm scale effect } \\ +\sum_{j} \sum_{f \in \mathcal{X}_{j}^{p}} s_{i j f_{0}} \% \Delta\left(\frac{N_{i j f}}{M_{i f}}\right) & \text { permanent firm intensity effect } \\ +\sum_{j} \sum_{f \in \mathcal{X}_{j}^{n}} \frac{N_{i f f}}{N_{i_{0}}}-\sum_{j} \sum_{f \in \mathcal{X}_{j}^{o}} \frac{N_{i j f_{0}}}{N_{i_{0}}} & \text { net new firm contribution } \\ +R_{i} & \text { residual term, }\end{cases} \end{cases}
$$

where $M_{j f}$ measures the overall employment and $N_{i j f}$ the skill-specific employment in firm $f$. The sets $\mathcal{X}_{j}^{p}, \mathcal{X}_{j}^{n}$, and $\mathcal{X}_{j}^{o}$, respectively, denote permanent $(p)$ firms, new $(n)$ firms, and old (o) firms in industry $j$, respectively. The variable $s_{i j f_{0}}=N_{i j f_{0}} / N_{i 0}$ is the share of all workers with skill level $i$ in

${ }^{17}$ For a similar strategy, see Hanson and Slaughter (2002). 
the overall tradable sector that is employed in (permanent) firm $f$ in the base period 0 and can thus be interpreted as a firm/skill group-specific weight. Finally, $N_{i j f}$ in the third row of the bracketed portion of (3) is the skill-specific employment in a new firm at the end of the observation period, and $N_{i j f_{0}}$ is the skill-specific employment in an old firm at the start of the observation period. ${ }^{18}$ For details of this derivation, see Appendix B, Section B2. Following our earlier discussion, the first term in equation (3) captures the contribution of changes in the size of permanent firms $\left(\% \Delta M_{j f}\right)$ to the absorption of changes in local labor supply, the second term the contribution of changes in relative factor inputs within a permanent firm $\left(\% \Delta\left(N_{i j f} / M_{i f}\right)\right)$, and the third term the contribution through the creation and destruction of firms. The fourth term captures the residual component. ${ }^{19}$

With this extended decomposition, we then proceed as described above, by regressing each of the four components on the region-specific relative changes in employment, conditional on a full set of region fixed effects $\theta_{r}$ and skill group fixed effects $\mu_{i}$. These latter account for scale or intensity changes common to all firms and skill groups in a region and exogenous changes in the relative use of different labor types in all firms and regions, respectively. For instance, the estimation equation for the permanent firm scale effect is then given by

$$
\sum_{j_{r}} \sum_{f \in \mathcal{X}_{j r}^{p}} s_{i j f_{0}} \times \% \Delta M_{i f}=\theta_{r}+\mu_{i}+\beta_{1} \% \Delta N_{i r}+\varepsilon_{i r}^{\text {scale }}
$$

and due to the adding-up property, $\hat{\beta}_{1}$ can be interpreted as the fraction of the change in skill-specific local employment that is absorbed through changes in the relative size of firms within a region.

\section{Data and Descriptive Evidence}

The data used for analysis, which cover West Germany only (hereafter, Germany), ${ }^{20}$ were provided by the Institute for Employment Research $(\mathrm{IAB})$ and comprise complete employment histories of all wage earners and salaried employees who are subject to social security contributions. ${ }^{21}$ Most important for our purposes, the data include a unique identifier for the firm in which an individual is working in a given year, which allows construction of a yearly panel for all firms in Germany that includes in-

${ }^{18}$ It should be noted that whenever a variable refers to the end of the observation period, we drop the time subscript for simplicity.

19 The residual term is given by $R_{i}=\sum_{j} \sum_{f \in \mathcal{X}^{p}} s_{i j f_{0}} \% \Delta M_{i f} \times \% \Delta\left(N_{i f f} / M_{i f}\right)$.

${ }^{20}$ West Germany's unification with East Germany took place on October 3, 1990 , but data on East Germany are only included in our social security data from 1992 onward. We therefore focus exclusively on labor market regions in West Germany, excluding Berlin.

${ }^{21}$ The data do not cover the self-employed, civil servants, and military personal. In $2001,77.2 \%$ of all workers in Germany were covered by the social security system (Bundesagentur für Arbeit 2004). 
formation on the firm's skill-specific employment and wages, industry, and region of operation. ${ }^{22}$ The labor market regions in our analysis are aggregates of Germany's 326 counties, which take commuter flows into account in order to better reflect separate local labor markets. Overall, there are 204 labor market regions, with an average population of around 315,000 individuals in 1995. One major advantage of using the entire workforce is that we can observe all firms rather than being biased, as are most firm-level data sets, toward large businesses (e.g., the US Annual Survey of Manufactures). Since most firms are small, with about 20 employees on average, such a focus could lead to potentially misleading conclusions.

We base our analysis on all individuals of ages 15-64 who work fulltime. We differentiate between three skill groups based on educational level, which we classify as low, medium, and high. Individuals with a low educational level are those without postsecondary education; those with a medium educational level have obtained postsecondary vocational or apprenticeship degrees; those with a high educational level have attended college. This classification is standard in the German context (see, e.g., Antonczyk, Fitzenberger, and Sommerfeld 2010).

We distinguish 44 two-digit industries that produce tradable goods,${ }^{23}$ a group in which, following Hanson and Slaughter (2002), we include manufacturing, agriculture, mining, finance, real estate, business services, and legal services. For a detailed overview of the individual industries and a number of key indicators, see table C1 in Appendix C. As shown in column 1 of that table, the largest tradable industry in 1995 was manufacture of electrical equipment, which, with around 818,000 employees, accounted for $10.0 \%$ of the overall full-time employment in the tradable sector in that year. Between 1985 and 1995, overall employment declined by 3.6\% to around 8.2 million, but the variation in employment growth across indus-

${ }^{22}$ The wage records in the IAB data sample are top-coded at the social security contribution ceiling, which can be severe for individuals in the highest skill group. Across regions, the mean fraction of individuals with censored wage observations is .6\% for the low-skilled, $5.0 \%$ for the medium-skilled, and $41.6 \%$ for the highlyskilled. We impute right-censored wages by first estimating for each year separately a Tobit model with a standard set of socioeconomic wage determinants (gender, citizenship, education, potential experience, region, and industry) and then adding a random error term to the predicted value of each censored observation, ensuring that the imputed wage lies above the censoring threshold (see Gartner [2004] for details). To be less susceptible to these imputed wages, we use median wages by skill group throughout the analysis. All wages are gross daily wages in real 1995 euros based on the consumer price index for all private households.

${ }^{23}$ We use the 1973 industry classification provided in the IAB data, according to which there are a further 35 industries that produce nontradable goods. Because the number of observations is small, we pool the following two-digit industries: $5-8,9-11,17 / 18,23 / 24,28 / 29,31 / 32,35 / 36,47-51,57 / 58$, and 93/94. 
tries was substantial, ranging from a decrease of $51.3 \%$ in the manufacture of apparel to an increase of $73.3 \%$ in architecture and engineering firms.

As stated above, for comparability with other studies, we limit in some specifications the tradable sector to manufacturing industries only. In table $\mathrm{C} 1$, we use an asterisk to designate all industries in the tradable sector that do not engage in manufacturing. ${ }^{24} \mathrm{We}$ find that $78 \%$ of all full-time employees in the tradable sector work in manufacturing industries. To illustrate the effect of aggregation on the estimated relative contributions of scale and intensity adjustments, we also use a finer, three-digit level industry classification, which distinguishes between 296 industries.

Table 1 summarizes the most relevant information for the firms in our data set. In 1995, a total of 402,195 firms were operating in the 44 tradable industries, 226,908 of them in the manufacturing sector. About half were already in existence in 1985 (permanent firms), while another half were newly established in the 10 years between 1985 and 1995. As could be expected, firms in the tradable sector that existed in both 1985 and 1995 were typically larger than both new and old firms, with 31.0 full-time employees on average in 1995, compared to 8.0 employees in new firms and 10.1 employees in firms that closed down by 1995 . The average firm size was 23.4 full-time workers in 1985 but declined by $12.6 \%$ to 20.4 workers in 1995. Average firm size in the manufacturing sector was somewhat larger, with 28.3 full-time workers in 1995.

In 1985 , on average $35.8 \%$ of workers employed in a region's tradable sector were low-skilled, $61.0 \%$ were medium-skilled, and 3.2\% were highly-skilled. ${ }^{25}$ In the decade thereafter, the share of low-skilled workers dropped by on average $28.5 \%$ to $25.6 \%$, the share of medium-skilled workers increased moderately by $12.9 \%$ to $68.8 \%$, and the share of highskilled workers increased substantially by $87.8 \%$ to $5.6 \%$. Relative skill shares in the manufacturing sector are comparable. The substantial overall shift in skill shares toward more highly educated workers reflects the secular increases in both high-skilled labor supply (because of higher college graduation rates) and high-skilled labor demand (due to, e.g., skillbiased technological change) that are also observable in many other developed economies over the 1980s and 1990s and which we account for in our estimations by including a full set of skill fixed effects.

${ }^{24}$ The three biggest tradable but nonmanufacturing industries are the financial intermediation and insurance industry, legal advice and business consulting, and architecture and engineering firms.

25 These estimates are unweighted averages across all 204 labor market regions. Note that the share of college-educated workers in the IAB data is lower than the corresponding figure from the German microcensus because the former does not include self-employed individuals and civil servants, many of whom have college degrees. 
Table 1

Descriptive Statistics

\begin{tabular}{|c|c|c|c|c|c|c|}
\hline & \multicolumn{3}{|c|}{ Tradable Sector } & \multicolumn{3}{|c|}{ Manufacturing Sector } \\
\hline & 1985 & 1995 & $\begin{array}{c}\% \\
\text { Change }\end{array}$ & 1985 & 1995 & $\begin{array}{c}\% \\
\text { Change }\end{array}$ \\
\hline No. of firms & 364,703 & 402,195 & 10.3 & 235,426 & 226,908 & -3.6 \\
\hline No. of permanent firms & & 216,978 & & & 141,808 & \\
\hline No. of new firms & & 185,217 & & & 85,100 & \\
\hline No. old firms $\dagger$ & 147,725 & & & 93,618 & & \\
\hline Average size & 23.4 & 20.4 & -12.6 & 30.0 & 28.3 & -5.8 \\
\hline Average size permanent firms & & 31.0 & & & 38.0 & \\
\hline Average size new firms & & 8.0 & & & 12.2 & \\
\hline Average size old firms & 10.1 & & & 12.8 & & \\
\hline \% Low skill & $\begin{array}{l}35.8 \\
(5.5)\end{array}$ & $\begin{array}{l}25.6 \\
(4.9)\end{array}$ & $\begin{array}{r}-28.5 \\
(6.1)\end{array}$ & $\begin{array}{l}37.9 \\
(5.4)\end{array}$ & $\begin{array}{l}27.6 \\
(5.0)\end{array}$ & $\begin{array}{r}-27.2 \\
(6.9)\end{array}$ \\
\hline \% Medium skill & $\begin{array}{l}61.0 \\
(4.8)\end{array}$ & $\begin{array}{l}68.8 \\
(4.5)\end{array}$ & $\begin{array}{l}12.9 \\
(5.5)\end{array}$ & $\begin{array}{l}59.3 \\
(4.8)\end{array}$ & $\begin{array}{l}67.7 \\
(4.8)\end{array}$ & $\begin{array}{l}14.3 \\
(5.8)\end{array}$ \\
\hline \% High skill & $\begin{array}{c}3.2 \\
(2.2)\end{array}$ & $\begin{array}{c}5.6 \\
(3.3)\end{array}$ & $\begin{array}{c}87.8 \\
(34.5)\end{array}$ & $\begin{array}{c}2.8 \\
(2.0)\end{array}$ & $\begin{array}{c}4.7 \\
(2.8)\end{array}$ & $\begin{array}{c}80.8 \\
(36.5)\end{array}$ \\
\hline Wage low skill & $\begin{array}{l}51.4 \\
(7.3)\end{array}$ & $\begin{array}{l}60.6 \\
(7.5)\end{array}$ & $\begin{array}{l}18.3 \\
(6.7)\end{array}$ & $\begin{array}{l}51.8 \\
(7.2)\end{array}$ & $\begin{array}{l}61.6 \\
(7.3)\end{array}$ & $\begin{array}{l}19.6 \\
(6.5)\end{array}$ \\
\hline Wage medium skill & $\begin{array}{l}67.6 \\
(6.4)\end{array}$ & $\begin{array}{l}78.3 \\
(7.0)\end{array}$ & $\begin{array}{l}15.9 \\
(3.2)\end{array}$ & $\begin{array}{l}67.4 \\
(6.6)\end{array}$ & $\begin{array}{l}78.1 \\
(7.3)\end{array}$ & $\begin{array}{l}15.9 \\
(3.4)\end{array}$ \\
\hline Wage high skill & $\begin{array}{l}123.7 \\
(17.6)\end{array}$ & $\begin{array}{l}128.6 \\
(14.7)\end{array}$ & $\begin{array}{c}4.7 \\
(8.3)\end{array}$ & $\begin{array}{l}129.0 \\
(18.6)\end{array}$ & $\begin{array}{l}136.1 \\
(16.6)\end{array}$ & $\begin{array}{c}6.2 \\
(8.6)\end{array}$ \\
\hline
\end{tabular}

NOTE.-Wages refer to median wages in each skill group. Right-censored wages have been imputed prior to calculating median wages. Standard deviations of the skill-specific variables (in parentheses) refer to variation across the 204 labor market regions in the sample.

$\uparrow$ The number of old firms refers to the number of firms that existed in 1985 but no longer existed in 1995.

Median wage growth between 1985 and 1995 was quite similar in the first two skill groups, increasing by $18.3 \%$ for low-skilled workers and $15.9 \%$ for medium-skilled workers. This observation is compatible with the relatively stable wage distribution in Germany over that period (see Dustmann, Ludsteck, and Schönberg 2009). Wage growth for high-skilled workers was lower at $4.7 \%$ but, due to extensive right-censoring of wages in this skill group, this figure has to be viewed with some caution.

To illustrate the variation in skill shares across firms, figure 1 plots for all firms existing in both 1985 and 1995 (i.e., permanent firms) the log skill ratio of medium-skilled workers to low-skilled workers in 1995 against the corresponding log ratio in 1985 . For reference, we superimpose a $45^{\circ}$ (dashed) line and a regression (solid) line regressing the 1995 skill shares on the 1985 skill shares. The upper scatterplot, which shows the raw data, reveals substantial variation in both 1985 and 1995, ranging from 0.50 (0.61) medium-skilled workers per 1 low-skilled worker at the first decile of the distribution to 6.00 (8.50) medium-skilled workers per 1 low-skilled worker at the ninth decile (for 1985 and 1995, respectively). The change in 


\section{Firm Level}

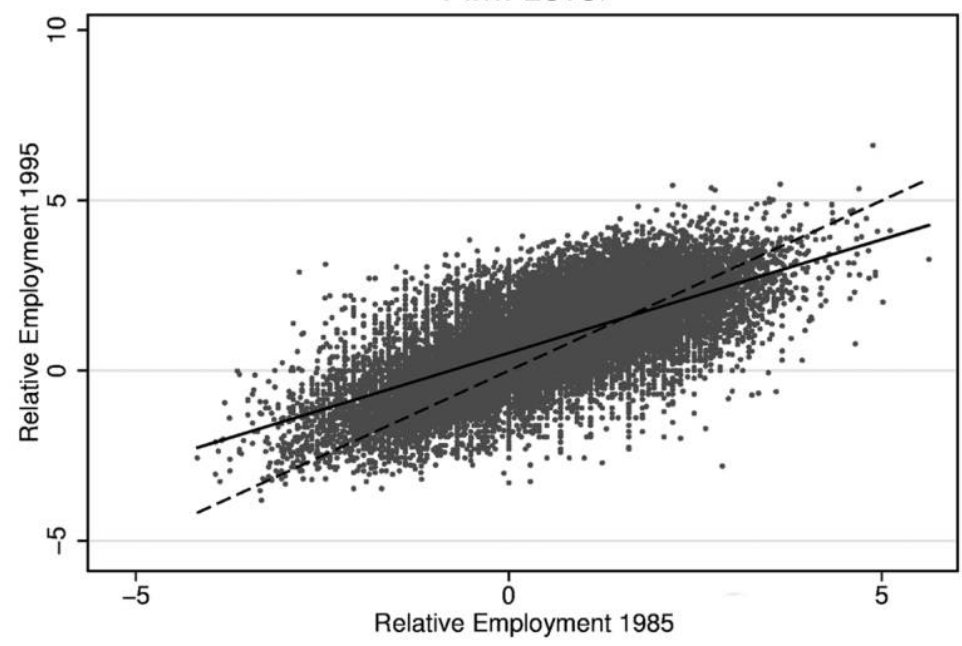

Firm Level - Residual

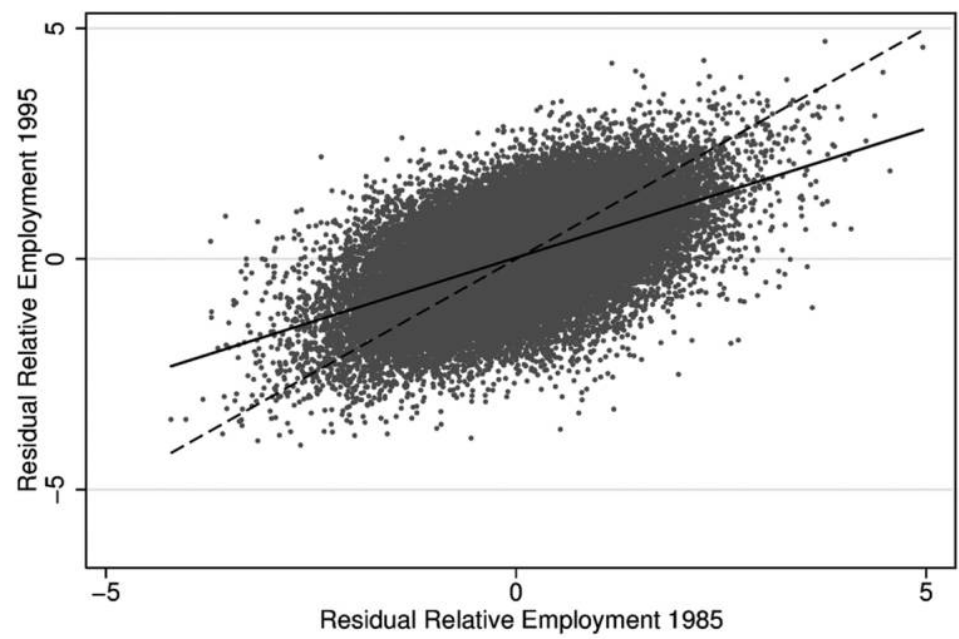

FIG. 1.-Relative employment, 1985 and 1995. The two graphs plot for all permanent firms in the tradable sector the log of the ratio of medium-skilled workers to low-skilled workers in 1995 against the corresponding log ratio in 1985. The upper graph shows the raw data. The lower graph shows the firm-level residual employment ratios after netting out region and three-digit industry fixed effects and their interactions separately in both years. 
log skill ratios between 1985 and 1995 also varies widely, ranging from -0.69 at the first decile to 1.39 at the ninth decile.

The lower scatterplot illustrates how much variation in skill shares is left after we eliminate any variation induced by general industry requirements and region-specific labor market conditions (and their interactions). To do this, we first regress the skill shares in each year on a full set of threedigit industry fixed effects interacted with region fixed effects and then plot the residual skill shares against each other. Although the variation in each year decreases considerably, from a standard deviation of 1.01 (1.05) in 1985 (1995) to a standard deviation of 0.85 (0.87), firms within the same three-digit industry and the same region still vary considerably in the skill ratios they employ. One reason could be that firms within even quite narrowly defined industries produce heterogeneous products, implying that within-industry changes in factor intensities as a response to labor supply shocks could mask between-firm scale adjustments-which is what we investigate in Section IV.D.

\section{Results}

\section{A. Wage Responses}

Table 2 shows the estimates of the parameter $\gamma$ in equation (2). These estimates can be interpreted as the percentage change in relative skillgroup-specific wages in response to a $1 \%$ increase in skill-group-specific

Table 2

Wage Impact of Changes in the Skill-Specific Labor Force

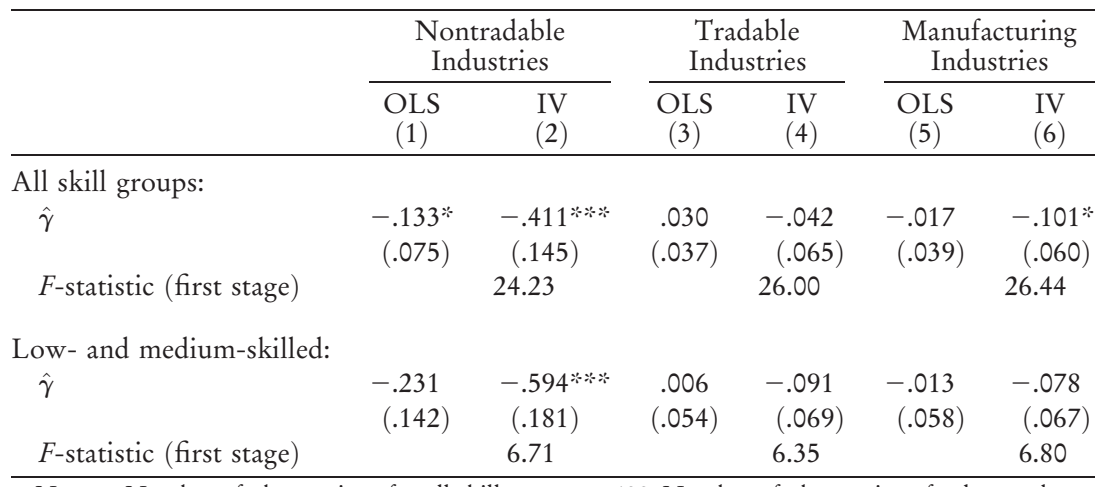

NOTE.- Number of observations for all skill groups $=408$. Number of observations for low and medium skilled $=612$. The dependent variable is the change in the median wage of each skill group between 1985 and 1995. Right-censored wages have been imputed prior to calculating median wages. Robust standard errors are reported in parentheses and are clustered on the regional level. Regressions are weighted by $\left(1 / N_{i}^{85}+1 / N_{i}^{95}\right)^{-1 / 2}$, where $N_{i}^{t}$ represents the regional employment in skill group $i$ in year $t$ based on which the median wages are calculated.

* Statistically significant at the $10 \%$ level.

*** Statistically significant at the $1 \%$ level. 
labor supply. The upper panel of the table reports results for all three education groups, while the lower panel reports results only for the lowand medium-education groups. ${ }^{26}$ Columns $1-2$ report results for nontradable industries, columns 3-4 give results for tradable industries, and columns 5-6 present results for the manufacturing sector only. Unevennumbered columns refer to OLS results and even-numbered columns to IV results. We discuss and graphically illustrate the first-stage regressions in Appendix D.

For the nontradable sector, our estimates indicate that changes in local labor supply have a significantly negative impact on wages. Both OLS and IV regressions show that relative wages decrease for those skill groups that experience supply increases. The IV results are larger than the OLS results, which is compatible with a partial response by regional labor supply to positive wage shocks. The result in column 2 of the upper panel, for example, suggests that a $1 \%$ increase in the labor supply of a particular skill group because of immigration leads to a decrease in relative median wages for workers in that skill group of about $0.41 \%$. Compared to estimates in the spatial correlation literature on the wage impact of immigration, which are often close to zero (see Okkerse [2008] for an overview of this literature), this elasticity is large. However, existing studies do not distinguish between the tradable and nontradable sector. When we pool all workers in our sample, the IV estimate becomes an insignificant -.040 (.059). These findings suggest that the impact of immigration on wages should be sought in the nontradable sector. Our study is, to the best of our knowledge, the first that draws this distinction when estimating the wage impact of immigration.

Turning to tradable industries, the OLS results reported in column 3 of table 2 indicate no effect of changes in relative skill-specific labor supply on relative wages using either all three skill groups or low- and mediumskilled workers only. The IV results turn negative but remain small and statistically not significantly different from zero. The wage elasticity is estimated at around -.042 using all three education groups and -.091 using only medium-skilled and low-skilled workers. The corresponding results for wages in the manufacturing sector are equally small in magnitude.

Taken together, these results suggest that immigration affects wages in the nontradable sector but has no effect on the wages of workers employed in the tradable sector. ${ }^{27}$ One possible explanation is that, in contrast to

${ }^{26}$ One motivation for estimating separately for workers with only low or medium education is the extensive right-censoring among the group of highly-skilled workers, particularly in the tradable and manufacturing sector. As a result, in these sectors, a nonnegligible number of observations for this group of workers is based on imputed rather than observed wages.

${ }^{27}$ We could in principle estimate wage equations on the firm level; when we do 
those in the nontradable sector, firms in the tradable sector are unable to adjust wages because of fixed output prices set on national or international markets and that workers are insufficiently mobile to respond to small wage changes in order to equilibrate wages across sectors. ${ }^{28}$ One possible reason for such immobility could, in turn, be Germany's distinctly sectorspecific vocational training system.

For the subsequent analysis, the most important insight provided by table 2 is the absence of any large or significant effect of changes in local labor supply on wages in the tradable sector. Within our analytical framework, this finding suggests that in that sector, adjustments may have taken place through either changes in output mix or changes in technology, two options we now investigate. ${ }^{29}$

\section{B. Adjustments through the Output Mix, Technology, and Firm Turnover}

We now decompose the overall change in region- and skill-specific employment into its various components using the decomposition presented in equation (3), which distinguishes between scale and intensity effects of firms that existed in both 1985 and 1995, the contribution of new and exiting firms, and a residual term. As demonstrated in table 1, new and exiting firms represent a large fraction of the firm population and employ a considerable share of workers. Not only may both new and exiting firms

so by OLS, our results are similar to those obtained from the regional-level regressions: there is no evidence of a strong effect of changes in relative skill-specific employment on relative wages. OLS estimation on the firm level, however, may lead to biased estimates due to the potential endogeneity of changes in firm-specific relative factor inputs. Moreover, under the reasonable assumption that labor is

${ }^{28}$ Monras (2011) explores how such worker sluggishness could impede the adjustment process to local labor supply shocks.

${ }^{29}$ Another reason for a differential response to labor supply shocks in tradable vs. nontradable industries could be differences in wage rigidities. Wages in the tradable sector may be more rigid than in the nontradable sector because of labor market institutions such as a wider union coverage. To explore this issue, we use information on the degree of union coverage in the two sectors in the year 1995, provided in the IAB Establishment Panel (see Fischer et al. [2008] for details on this data set). As explained in Dustmann and Schönberg (2012), in Germany, all firms that are members of the employers' association pay union-negotiated wages, but firms that are not members are not bound by union contracts no matter what the worker's union status. Of the 3,921 West German firms sampled that year, 61\% of those belonging to the nontradable sector were covered by an industry-wide union agreement, compared to only $51 \%$ of firms in the tradable sector. Thus, wage rigidities as a result of stronger union influence are unlikely to explain the differential impact of labor supply shocks on wages across sectors. 
contribute substantially to the absorption of labor supply shocks, but new firms may also be in a better position than existing firms to react to labor supply changes by adopting appropriate technologies.

In table 3, we present the results from the firm-level decomposition, distinguishing between the tradable sector overall (upper panel) and the manufacturing sector (lower panel). The OLS estimates for the tradable sector show that $23.3 \%$ of changes in skill-specific employment are absorbed by scale adjustments, while $34.3 \%$ are absorbed by intensity adjustments and $23.8 \%$ by new and exiting firms, with $18.6 \%$ captured by the residual term. These estimates suggest that new and exiting firms contribute to the absorption of changes in labor supply to about the same extent as scale adjustments of permanent firms. The corresponding results for the manufacturing sector only, reported in the first row of the lower panel, are similar, with a somewhat higher intensity effect and a correspondingly lower effect through new and exiting firms. Having only a descriptive interpretation, these OLS results, however, cannot reveal the direction of causality.

To identify firm adaptation to unforeseen labor supply shocks, we apply the IV strategy explained in Section II.A using predictions of immigrant inflows into particular regions and skill groups as instruments for local employment changes. For the tradable sector as a whole, row 2 of table 3 shows that the fraction explained by scale adjustments decreases to $13.7 \%$, the contribution of within-firm adjustments increases to about

Table 3

Decomposition of Changes in Labor Supply on the Firm Level

\begin{tabular}{|c|c|c|c|c|}
\hline & $\begin{array}{c}\text { Permanent Firm } \\
\text { Scale Effect } \\
(1)\end{array}$ & $\begin{array}{c}\text { Permanent Firm } \\
\text { Intensity Effect } \\
(2)\end{array}$ & $\begin{array}{c}\text { Net New Firm } \\
\text { Contribution } \\
(3)\end{array}$ & $\begin{array}{c}\text { Residual } \\
\text { Term } \\
(4)\end{array}$ \\
\hline \multicolumn{5}{|c|}{ Tradable sector: } \\
\hline OLS & $\begin{array}{l}.233 \% * * \\
(.027)\end{array}$ & $\begin{array}{l}.343 * * * \\
(.045)\end{array}$ & $\begin{array}{l}.238 * * * x \\
(.023)\end{array}$ & $\begin{array}{l}.186 \% * * \\
(.043)\end{array}$ \\
\hline IV & $\begin{array}{l}.137 \\
(.120)\end{array}$ & $\begin{array}{l}.712 * * * \% \\
(.141)\end{array}$ & $\begin{array}{l}.145 * * \\
(.057)\end{array}$ & $\begin{array}{c}.007 \\
(.129)\end{array}$ \\
\hline \multicolumn{5}{|c|}{ Manufacturing sector: } \\
\hline OLS & $\begin{array}{l}.211 \% * * \\
(.036)\end{array}$ & $\begin{array}{l}.434 * * * \\
(.051)\end{array}$ & $\begin{array}{l}.142^{* * * *} \\
(.021)\end{array}$ & $\begin{array}{l}.214 \% * * \\
(.055)\end{array}$ \\
\hline IV & $\begin{array}{l}.146 * * * \\
(.039)\end{array}$ & $\begin{array}{l}.512 * * * \\
(.096)\end{array}$ & $\begin{array}{l}.127^{* * * * 6} \\
(.041)\end{array}$ & $\begin{array}{l}.215^{* *} \\
(.086)\end{array}$ \\
\hline
\end{tabular}

NOTE.-All regressions use 612 observations and include a full set of skill and region fixed effects. Robust standard errors are reported in parentheses. Regressions are weighted by $\left(1 / N_{r}^{85}+1 / N_{r}^{95}\right)^{-1 / 2}$, where $N_{r}^{t}$ represents overall employment in tradable industries (upper panel) or manufacturing industries (lower panel) in region $r$ in year $t$. The first-stage $F$-statistic of the instrument is 33.99 in the upper panel and 43.34 in the lower panel.

$*$ Statistically significant at the $5 \%$ level.

*** Statistically significant at the $1 \%$ level. 
$71.2 \%$, and the net contribution of new firms drops to about $14.5 \%$. Results for the manufacturing sector are qualitatively similar, although with a smaller estimate for the intensity effect. Overall, these results suggest that firm absorption of exogenously allocated workers takes place predominantly through the employment of production technologies that use the more abundant factor more intensively. The relatively larger scale effect estimated in the OLS specification, in contrast, seemingly reflects scale expansions of firms attracting workers into the specific labor market rather than a mechanism to absorb exogenous changes in local labor supply. The results also show that new and exiting firms make an important contribution to the absorption of labor supply shocks, similar in magnitude to the absorption through changes in the output mix. ${ }^{30}$ Given its importance, and in order to obtain an overall assessment of the relative importance of output and technology adjustments, it would be useful to interpret the new and exiting firms' contribution as either a scale or an intensity adjustment. In the next section, we propose a way to distinguish between the two.

\section{The Contribution of New Firms}

The net new firm contribution reported in table 3 could be due to a scale effect (i.e., new firms entering predominantly industries that use the more abundant production factor more intensively) or an intensity effect (i.e., new firms entering industries that produce a particular product choosing technologies that make more relative use of the more abundant factor). Because these firms did not exist either at the beginning or at the end of the observation window, however, we cannot use the firm-specific growth rates in scale and skill-specific factor intensities to distinguish between the two (as in the case of permanent firms). An alternative way to decompose the net contribution of new firms is to benchmark it against their industry of operation in the year in which they are created or shut down. Using this principle, for each entering or exiting firm in our 10-year observation window, we compute the average relative factor inputs of its two-digit industry in the year of entry or exit. The firm's contribution in that particular year can then be interpreted as either a pure scale effect, if its factor intensity coincides with the contemporaneous industry average, or as an intensity effect, if it enters and exits with different relative factor inputs. After the year of entry (before the year of exit), new (old) firms can be considered permanent firms and their growth in scale and factor intensity treated in the same way as for our initial set of permanent firms. Following this line of argument, we decompose the net contribution of new and

${ }^{30}$ For US evidence on the role of firm creation in response to immigrant supply shocks, see Olney (2013). It should be interesting to investigate whether immigrants directly contribute to the start-up of new firms, as suggested in Beaudry, Green, and Sand (2013). Unfortunately, we do not observe this information in our data. 
old firms in the last row of equation (3) into a scale component and an intensity component, each of which is the sum of the corresponding contribution at entry or exit and the contribution over time. For details of this decomposition, see Appendix B, Section B3.

In table 4, we report the OLS and IV results from this more detailed decomposition. In the last column, we report the overall net contribution of new firms, taken directly from table 3. The first row of the OLS and IV panels reports the decomposition of the net effect into an overall scale and an overall intensity effect, while the second row of each panel reports the further decomposition into the corresponding contributions in the year of entry/exit and over time.

Focusing on the IV results, the estimates suggest that new firms tend to enter in those industries that use the more abundant factor more inten-

Table 4

Decomposition of New Firms' Contribution, Tradable Sector

\begin{tabular}{|c|c|c|c|c|c|c|}
\hline & \multicolumn{5}{|c|}{ Net New Firm Contribution } & \multirow[b]{3}{*}{$\begin{array}{c}\text { Total } \\
(6)\end{array}$} \\
\hline & \multicolumn{2}{|c|}{ Scale Effect } & \multicolumn{2}{|c|}{ Intensity Effect } & \multirow[b]{2}{*}{$\begin{array}{l}\text { Residual } \\
\text { Term } \\
(5)\end{array}$} & \\
\hline & $\begin{array}{c}\text { Entry } \\
(1)\end{array}$ & $\begin{array}{l}\text { Over } \\
\text { Time } \\
(2)\end{array}$ & $\begin{array}{c}\text { Entry } \\
(3)\end{array}$ & $\begin{array}{l}\text { Over } \\
\text { Time } \\
(4)\end{array}$ & & \\
\hline \multicolumn{7}{|l|}{ OLS: } \\
\hline \multicolumn{7}{|l|}{$\begin{array}{l}\text { Decomposition of the net } \\
\text { effect into an overall scale } \\
\text { and an overall intensity }\end{array}$} \\
\hline effect & \multicolumn{2}{|c|}{$\begin{array}{l}.093 * * * * \\
(.028)\end{array}$} & \multicolumn{2}{|c|}{$\begin{array}{l}.155^{* * * *} \\
(.047)\end{array}$} & $\begin{array}{r}-.010 \\
(.050)\end{array}$ & $\begin{array}{l}.238 * * * \\
(.023)\end{array}$ \\
\hline $\begin{array}{l}\text { Decomposition into the } \\
\text { corresponding contribu- } \\
\text { tions in the year of entry/ } \\
\text { exit and over time }\end{array}$ & $\begin{array}{l}.028 * * \\
(.012)\end{array}$ & $\begin{array}{l}.065^{* * * *} \\
(.024)\end{array}$ & $\begin{array}{l}.071 * * * \\
(.018)\end{array}$ & $\begin{array}{l}.083 * \\
(.048)\end{array}$ & $\begin{array}{r}-.010 \\
(.050)\end{array}$ & \\
\hline \multicolumn{7}{|c|}{ (100) } \\
\hline $\begin{array}{l}\text { Decomposition of the net } \\
\text { effect into an overall scale } \\
\text { and an overall intensity } \\
\text { effect }\end{array}$ & \multicolumn{2}{|c|}{$\begin{array}{l}.131 \\
(.115)\end{array}$} & \multicolumn{2}{|c|}{$\begin{array}{l}.192 \% \\
(.107)\end{array}$} & $\begin{array}{c}-.179 \\
(.128)\end{array}$ & $\begin{array}{l}.145^{* *} \\
(.057)\end{array}$ \\
\hline $\begin{array}{l}\text { Decomposition into the } \\
\text { corresponding contribu- } \\
\text { tions in the year of entry/ } \\
\text { exit and over time }\end{array}$ & $\begin{array}{l}.055^{*} \\
(.030)\end{array}$ & $\begin{array}{l}.077 \\
(.103)\end{array}$ & $\begin{array}{l}.009 \\
(.029)\end{array}$ & $\begin{array}{l}.183 * \\
(.108)\end{array}$ & $\begin{array}{c}-.179 \\
(.128)\end{array}$ & \\
\hline
\end{tabular}

NOTE.-All regressions use 612 observations and include a full set of skill and region fixed effects. Robust standard errors are reported in parentheses. Regressions are weighted by $\left(1 / N_{r}^{85}+1 / N_{r}^{95}\right)^{-1 / 2}$, where $N_{r}^{t}$ represents overall employment in tradable industries in region $r$ in year $t$. The first-stage $F$-statistic of the instrument is 33.99 .

* Statistically significant at the $10 \%$ level.

$*$ Statistically significant at the $5 \%$ level.

*** Statistically significant at the $1 \%$ level. 
sively (col. 1), thereby contributing to the absorption of exogenous changes in local labor supply. In contrast, relative to the industry average in their year of entry (exit), new (old) firms do not appear to employ factor intensities that are conducive to a further absorption of local supply shocks (col. 3). What does play an important role, however, are adjustments in factor intensity in these new firms through ongoing changes after market entry (col. 4). This could be because young firms face comparatively low adjustment costs in their first years of operation, which could facilitate their adapting to local conditions. Overall, table 4 suggests that immigrationinduced supply shocks promote the creation of new firms in industries that use the now more abundant type of labor intensively in their production process and that these new firms are, over the course of time, particularly responsive to local supply conditions with respect to their choice of production technology.

\section{Levels of Aggregation}

One important shortcoming of an industry-level decomposition is that it may mask scale effects that occur across firms but within industries, especially when firms within an industry produce heterogeneous products. We now assess the magnitude of this possible aggregation error, by decomposing the adjustment to changes in relative employment into between and within adjustments on three levels of aggregation: two-digit industry and three-digit industry (which overall distinguish 79 and 296 industries, respectively) and individual firm. To make comparisons across aggregation levels meaningful, we exclude new and exiting firms (which on the industry level are subsumed under the corresponding industry classification) from our sample prior to estimation by adjusting the overall change in skill-specific regional employment accordingly. ${ }^{31}$

Using only permanent firms that existed in both 1985 and 1995, consider the correspondence between the scale effect that would be measured on the industry level and the scale effect measured on the firm level: ${ }^{32}$

$$
\underbrace{\sum_{j} s_{i j 0} \% \Delta M_{j}}_{\text {industry scale effect }}=\underbrace{\sum_{j} \sum_{f \in \mathcal{X}_{j}^{p}} s_{i j f_{0}} \% \Delta M_{j f}}_{\text {permanent firm scale effect }}+\underbrace{\sum_{j} \sum_{f \in \mathcal{X}_{j}^{p}} s_{i j 0}\left(\frac{M_{i f_{0}}}{M_{j 0}}-\frac{N_{i j f_{0}}}{N_{i j o}}\right) \% \Delta M_{j f}}_{\text {permanent firm aggregation term scale }} .
$$

${ }^{31}$ More precisely, we obtain

$$
\frac{\Delta N_{i}}{N_{i_{0}}}-\left(\sum_{j} \sum_{f \in \mathcal{X}_{j}^{n}} \frac{N_{i j f}}{N_{i_{0}}}-\sum_{j} \sum_{f \in \mathcal{X}_{j}^{o}} \frac{N_{i j f_{0}}}{N_{i_{0}}}\right) \equiv \% \Delta N_{i}^{\mathrm{perm}} .
$$

${ }^{32}$ For the industry level decomposition, see App. B, with $j$ now denoting different industries. 
It follows from equation (4) that the scale effects measured on the firm and industry level will be the same if the last term in (4) is equal to zero, an outcome that happens trivially if all firms in the same industry $j$ produce with the same relative factor inputs in the base year. In this case, $\left(M_{i f_{0}} / M_{j 0}\right)-\left(N_{i j f_{0}} / N_{i j_{0}}\right)=0$ for all firms, and the industry-based scale effect will be identical to the firm-based scale effect. Such, however, is unlikely to be the case, given the substantial variation in relative factor inputs across firms even within the same industry and region (see fig. 1). More generally, the decompositions on the industry and firm level will lead to the same results as long as the factor intensities employed in different firms are uncorrelated with the firms' growth rates. If, however, those firms within an industry that are particularly intensive (relative to their size) in the use of a given skill input $i\left(\right.$ so that $\left.\left(M_{j f_{0}} / M_{j_{0}}\right)-\left(N_{i j f_{0}} / N_{i j_{0}}\right)<0\right)$ grow at a faster rate, then the aggregation term will be negative, meaning that an industry-level analysis will underestimate the contribution through scale adjustments, relative to a firm-level analysis.

Similarly, for the intensity effect we have:

$$
\underbrace{\sum_{j} s_{i j 0} \% \Delta\left(\frac{N_{i j}}{M_{j}}\right)}_{\text {industry intensity effect }}=\underbrace{\sum_{j} \sum_{f \in \mathcal{X}_{j}^{p}} s_{i j 0_{0}} \% \Delta\left(\frac{N_{i j f}}{M_{j f}}\right)}_{\text {permanent firm intensity effect }}+\underbrace{\sum_{j} \sum_{f \in \mathcal{X}_{j}^{p}} s_{i j f_{0}}\left(\frac{\frac{N_{i j f}}{M_{i f}}}{\frac{N_{i j f_{0}}}{M_{j f_{0}}}} \frac{\left(\frac{M_{i f}}{M_{i f_{0}}}-\frac{M_{j}}{M_{j_{0}}}\right)}{\frac{M_{j}}{M_{j_{0}}}}\right)}_{\text {permanent firm aggregation term intensity }} .
$$

Equation (5) shows that the intensity effect calculated at the firm level equals the intensity effect at the industry level if all firms in the same industry $j$ grow at the same rate (so there is no "between" effect within industries); in this case, $\left(M_{j f} / M_{j f_{0}}\right)-\left(M_{j} / M_{j_{0}}\right)=0$. More generally, as long as the firms' growth rates (relative to the industry average) are uncorrelated with the change in their relative factor intensities, a firm-level estimation will lead to the same results as an industry-level estimation.

Table 5 reports the outcomes of distinguishing between the tradable sector (upper panel) and manufacturing firms within the tradable sector (lower panel) for two-digit industries, three-digit industries, and the firm level. The first three columns report OLS results, and the last three, IV results. The OLS estimates for the tradable sector on the two-digit industry level suggest that $15.3 \%$ of changes in skill-specific employment are absorbed by scale adjustments, while $64.4 \%$ are absorbed by intensity adjustments, with $20.3 \%$ captured by the residual term. The relative proportion of the scale and intensity effects on the firm level are almost identical to those reported in table 3 (with a ratio of about 0.68 for OLS) but are larger in absolute size because of the focus on permanent firms only, 
Table 5

Decomposition of Changes in Labor Supply by Level of Aggregation

\begin{tabular}{|c|c|c|c|c|c|c|}
\hline & \multicolumn{3}{|c|}{ OLS } & \multicolumn{3}{|c|}{ IV } \\
\hline & $\begin{array}{l}\text { Scale } \\
\text { Effect }\end{array}$ & $\begin{array}{l}\text { Intensity } \\
\text { Effect }\end{array}$ & $\begin{array}{l}\text { Residual } \\
\text { Term }\end{array}$ & $\begin{array}{l}\text { Scale } \\
\text { Effect }\end{array}$ & $\begin{array}{c}\text { Intensity } \\
\text { Effect }\end{array}$ & $\begin{array}{c}\text { Residual } \\
\text { Term }\end{array}$ \\
\hline \multicolumn{7}{|l|}{ Tradable sector: } \\
\hline Two-digit industry level & $\begin{array}{l}.153^{* * *} \\
(.015)\end{array}$ & $\begin{array}{l}.644 * * * \\
(.027)\end{array}$ & $\begin{array}{l}.203 * * * \\
(.023)\end{array}$ & $\begin{array}{c}.006 \\
(.043)\end{array}$ & $\begin{array}{l}.831 * * * 6 \\
(.069)\end{array}$ & $\begin{array}{l}.163^{* * *} \\
(.055)\end{array}$ \\
\hline Three-digit industry level & $\begin{array}{l}.207^{* * * *} \\
(.019)\end{array}$ & $\begin{array}{l}.597 * * * * 6 \\
(.033)\end{array}$ & $\begin{array}{l}.197 * * * \\
(.030)\end{array}$ & $\begin{array}{c}.038 \\
(.050)\end{array}$ & $\begin{array}{l}.805^{* * * *} \\
(.083)\end{array}$ & $\begin{array}{l}.157^{* * *} \\
(.061)\end{array}$ \\
\hline Firm level & $\begin{array}{l}.297 * * * * \\
(.030)\end{array}$ & $\begin{array}{l}.435^{* * *} \\
(.057)\end{array}$ & $\begin{array}{l}.268 * * * \\
(.052)\end{array}$ & $\begin{array}{l}.166 \\
(.145)\end{array}$ & $\begin{array}{l}.824 * * * \\
(.152)\end{array}$ & $\begin{array}{c}.010 \\
(.153)\end{array}$ \\
\hline \multicolumn{7}{|l|}{ Manufacturing sector: } \\
\hline Two-digit industry level & $\begin{array}{l}.124 \% * * \% \\
(.012)\end{array}$ & $\begin{array}{l}.681 * * * \\
(.025)\end{array}$ & $\begin{array}{l}.196 * * * \\
(.024)\end{array}$ & $\begin{array}{l}.116 \% * * \% \\
(.023)\end{array}$ & $\begin{array}{l}.671^{* * * *} \\
(.055)\end{array}$ & $\begin{array}{l}.214 \% * * \\
(.052)\end{array}$ \\
\hline Three-digit industry level & $\begin{array}{l}.179 \% * * \\
(.016)\end{array}$ & $\begin{array}{l}.617^{* * * *} \\
(.034)\end{array}$ & $\begin{array}{l}.204 * * * \\
(.033)\end{array}$ & $\begin{array}{l}.156 \% * * \\
(.031)\end{array}$ & $\begin{array}{l}.622 * * * 6 \\
(.067)\end{array}$ & $\begin{array}{l}.222 * * * \\
(.059)\end{array}$ \\
\hline Firm level & $\begin{array}{l}.251 \% * * \\
(.033)\end{array}$ & $\begin{array}{l}.466 \% * * \\
(.055)\end{array}$ & $\begin{array}{l}.283 * * \% \\
(.056)\end{array}$ & $\begin{array}{l}.172 \% * * \\
(.044)\end{array}$ & $\begin{array}{l}.565^{* * * *} \\
(.109)\end{array}$ & $\begin{array}{l}.263^{* * * x} \\
(.100)\end{array}$ \\
\hline
\end{tabular}

NOTE.-All regressions use 612 observations and include a full set of skill and region fixed effects. The sample only comprises permanent firms. Robust standard errors are reported in parentheses. Regressions are weighted by $\left(1 / N_{r}^{85}+1 / N_{r}^{95}\right)^{-1 / 2}$, where $N_{r}^{t}$ represents overall employment in all permanent firms in tradable industries (upper panel) or manufacturing industries (lower panel) in region $r$ in year $t$. The firststage $F$-statistic of the instrument is 32.08 .

** Statistically significant at the $5 \%$ level.

$* \%$ Statistically significant at the $1 \%$ level.

the omission of the net new firm effects, and the summing property of our decomposition. When we move to finer levels of disaggregation (threedigit industry and firm level), the relative fraction of within adjustment decreases, while the scale adjustment increases. This finding is compatible with the intensity effect on the industry level being partially explained by scale adjustments within industries. The figures for the manufacturing sector are similar (lower panel of the table): again, whereas a two-digit industry classification suggests that only $12.4 \%$ of supply changes are absorbed by scale effects, this number increases to $17.9 \%$ when industries are broken down into three-digit levels and to $25.1 \%$ when the data used are on the firm level, with a corresponding decrease in the contribution of the intensity effect. As before, however, these OLS results allow only a descriptive interpretation, referring to the absorption of both demand-and supply-induced changes in local employment.

Columns 4-6 of the table present the IV results. For the tradable sector as a whole, these results show that the fraction explained by scale adjustments drops to basically zero for the two- and three-digit industry classifications but increases to $16.6 \%$ when decomposed on the firm level. As regards the manufacturing sector only, the results suggest a larger role for scale adjustments to immigration-induced labor supply shocks. They also 
show, as before, that the smaller the level of disaggregation, the larger the scale effect: on the firm level, the numbers suggest that about $17.2 \%$ of labor supply shocks are absorbed through scale adjustments, $56.5 \%$ through intensity adjustments, and $26.3 \%$ are captured by the residual term.

These results consistently suggest that aggregation may lead to an underestimation of scale adjustments and an overestimation of intensity adjustments. However, this interpretation is based on the assumption that firms within an industry produce heterogeneous products, an assumption for which there is some evidence (see, e.g., Schott 2004; Broda and Weinstein 2006). If this is the case, it is likely they will do so employing different optimal skill ratios in the base period, a pattern for which figure 1 provides indeed strong evidence. As shown in equation (4), the scale effect will then be underestimated in an industry-level analysis if those firms within industries that use the factor whose supply increased more intensively grow faster than those who use it less intensively.

At the other extreme, if all firms in the same industry produced the same product, the between-firm within-industry changes might simply reflect differential growth of firms that produce the same product within an industry but choose different coexisting technologies (e.g., Beaudry and Green 2003, 2005). In this extreme case, a firm-level analysis could lead to an overestimation of the product mix adjustment and underestimation of the technology adjustment. Thus, industry- and firm-level analyses may be interpreted as bounds on the relative magnitude of the two different adjustment channels. In both cases, however, according to our results, intensity adjustments are far more important for absorbing labor supply shocks than scale adjustments, explaining between $57 \%$ and $67 \%$ of the overall employment changes in the manufacturing sector, and between $81 \%$ and $83 \%$ in the more broadly defined tradable sector. This key finding thus corroborates the results of Lewis (2003) and González and Ortega (2011), who, in a comparable set-up, find a within-industry contribution of $74 \%$ and $60 \%$, respectively.

\section{E. Extensions}

As a first extension of our standard decomposition, we make a distinction between the contributions of small versus large firms. This is motivated by the observation that, if firms produce multiple products, then even on the firm level, adjustments in relative factor intensities could result from changes in the product mix. If such is the case, we would expect this outcome to matter more for large firms than small firms. Defining a small firm as having at most 100 full-time employees in the base year (for new firms, the size limit refers to 1995), there were 1,241,971 small firms with an average of 6.8 workers and 23,344 large firms with an average of 379.7 workers operating in Germany in 1985. Overall full-time 
Table 6

Decomposition of Changes in Labor Supply on the Firm Level, Extensions

\begin{tabular}{|c|c|c|c|c|c|}
\hline & $\begin{array}{c}\text { Permanent Firm } \\
\text { Scale Effect }\end{array}$ & $\begin{array}{l}\text { Permane } \\
\text { Intensity }\end{array}$ & $\begin{array}{l}\text { Firm } \\
\text { Effect }\end{array}$ & $\begin{array}{c}\text { Net New Firm } \\
\text { Contribution }\end{array}$ & $\begin{array}{c}\text { Residual } \\
\text { Term } \\
\end{array}$ \\
\hline \multicolumn{6}{|c|}{ Large firms: } \\
\hline \multirow[t]{2}{*}{ OLS } & $.103 * * \%$ & \multicolumn{2}{|c|}{$171 * * * x$} & $.065 * * *$ & $.163 * * *$ \\
\hline & $(.020)$ & \multicolumn{2}{|c|}{$(.044)$} & $(.020)$ & $(.039)$ \\
\hline \multirow[t]{2}{*}{ IV } & .006 & \multicolumn{2}{|c|}{$.388 * * *$} & -.005 & .067 \\
\hline & $(.043)$ & \multicolumn{2}{|c|}{$(.138)$} & $(.039)$ & $(.096)$ \\
\hline \multicolumn{6}{|c|}{ Small firms: } \\
\hline \multirow[t]{2}{*}{ OLS } & $.130 * * *$ & \multirow{2}{*}{\multicolumn{2}{|c|}{$\begin{array}{l}.173 * * * \\
(.018)\end{array}$}} & $.173 * * *$ & .023 \\
\hline & $(.024)$ & & & $(.016)$ & $(.019)$ \\
\hline \multirow[t]{5}{*}{ IV } & .131 & \multicolumn{2}{|c|}{$325 * \% *$} & $149 * * *$ & -.061 \\
\hline & $(.105)$ & \multicolumn{2}{|c|}{$(.046)$} & $(.035)$ & $(.101)$ \\
\hline & \multirow{2}{*}{\multicolumn{3}{|c|}{$\begin{array}{l}\text { Permanent Firm } \\
\text { Intensity Effect }\end{array}$}} & \multirow{3}{*}{$\begin{array}{c}\text { Net New Firm } \\
\text { Contribution }\end{array}$} & \multirow{3}{*}{$\begin{array}{c}\text { Residual } \\
\text { Term }\end{array}$} \\
\hline & & & & & \\
\hline & Scale Effect & Idiosyncratic & Nationwide & & \\
\hline \multicolumn{6}{|c|}{ Nationwide: } \\
\hline \multirow[t]{2}{*}{ OLS } & $.233 * * *$ & $.276 * * *$ & $.067 * * * 6$ & $.238 * * *$ & $.186 * * *$ \\
\hline & $(.027)$ & $(.045)$ & $(.017)$ & $(.023)$ & $(.043)$ \\
\hline \multirow[t]{2}{*}{ IV } & .137 & $.585 \%$ & $.127 * * *$ & $.145^{* *}$ & .007 \\
\hline & $(.120)$ & $(.140)$ & $(.044)$ & $(.057)$ & $(.129)$ \\
\hline
\end{tabular}

NOTE.-All regressions include a full set of skill and region fixed effects. The number of observations is 612. Robust standard errors are reported in parentheses. Regressions are weighted by $\left(1 / N_{r}^{85}+1 / N_{r}^{95}\right)^{-1 / 2}$, where $N_{r}^{t}$ represents overall employment in tradable industries in region $r$ in year $t$. The first-stage $F$-statistic is 33.99 .

* Statistically significant at the $5 \%$ level.

$* * *$ Statistically significant at the $1 \%$ level.

employment was thus shared almost equally between these two groups $(48.8 \%$ vs. $51.2 \%)$. The first two panels in table 6 show the results of our firm-level decomposition (eq. [3]) for small and large firms separately. Both in the OLS and the IV estimations, the relative adjustment through changes in scale and factor intensities is quite similar for both firm types. As expected, the main difference lies in the contribution through the net creation of new firms. Since hardly any of the newly created or exiting firms are large, their contribution to the absorption of changes in local factor supplies is small, around $6.5 \%$ in the OLS and effectively zero in the IV estimations. Small new firms, on the other hand, contribute a significant share of $17.3 \%$ and $14.9 \%$, respectively, to the overall absorption.

The third panel of the table reports the results when we net out nationwide industry-specific changes in factor intensities prior to estimation, following the reasoning of Hanson and Slaughter (2002), who argue that these cannot be interpreted as a response to changes in local labor supply. After first calculating the nationwide percentage change in factor intensity, $\% \Delta^{N}\left(N_{i j} / M_{j}\right)$, for each two-digit industry and skill group, we then 
subtract this change from the actual change occurring in each permanent firm belonging to the given industry to obtain the component of the change in relative factor intensities that is idiosyncratic to each firm in a given region, $\% \Delta^{I}\left(N_{i j f} / M_{j f}\right)$ :

$$
\% \Delta^{I}\left(\frac{N_{i j f}}{M_{i f}}\right)=\% \Delta\left(\frac{N_{i f f}}{M_{i f}}\right)-\% \Delta^{N}\left(\frac{N_{i j}}{M_{j}}\right) .
$$

Substituting this equality into equation (3) leads to a new decomposition of the within-firm effect into a component for nationwide changes in factor intensities and an idiosyncratic region-specific component. According to the estimates in the third panel of table 6, in Germany, the latter component plays the dominant role: in the IV estimations, 58.5 percentage points of the original $71.2 \%$ can be attributed to such idiosyncratic changes in relative factor intensities and only 12.7 percentage points to nationwide changes in industry-specific relative factor intensities. Contrary to the conclusion by Hanson and Slaughter (2002), this finding indicates that firms in the same industries operating in different regions change their relative factor inputs differentially in response to local changes in factor supplies. Such differential behavior strongly supports the interpretation of our empirical results as reflecting endogenous technology adoption as a major adjustment mechanism to local supply changes.

\section{Conclusion}

This paper analyzes three channels by which local labor markets and the firms operating therein can absorb skill-specific changes in labor supply: wages, scale adjustments between production units, and factor intensity adjustments within production units. In contrast to previous work, we investigate these different adjustment channels on the firm level, which eliminates possible aggregation errors and allows an assessment of the contribution of new and exiting firms. To isolate the causal effect of local supply shocks from demand-driven supply changes, we instrument potentially endogenous changes in local labor supply with immigrant inflows that are driven by past settlement patterns of their conationals.

In a first step, we analyze the effect of changes in local labor supply on skill-specific wages. Although we find significant wage responses in the nontradable sector, there are no wage effects in the tradable sector, even when we instrument observed labor supply changes. This finding suggests that it may be important for studies on wage responses to immigration to distinguish between tradable and nontradable sectors. Focusing on the tradable sector (and the manufacturing sector therein), we find that more than two-thirds of the immigration-induced changes in relative skill supplies are absorbed by within-firm changes in relative factor 
intensities. Given that relative wages are constant, this result points to changes in production technology as an important adjustment mechanism to labor supply shocks.

While between-firm output mix adjustments are relatively small, the creation and destruction of firms plays an important additional role in the overall absorption of local supply shocks. New firms enter into industries and employ relative factor intensities in a way that is conducive to the absorption of the factor that has become more abundant.

Comparing results from an industry-level analysis with those from a firm-level analysis, we find that the former understates the relative contribution of scale adjustments because it does not take into account the heterogeneity of firms within an industry. In addition, although the relative importance of the different adjustment channels on the firm level does not vary significantly for existing firms of different sizes, the absorption through firm turnover results predominantly from small firms entering and exiting the labor market.

Overall, our findings are in line with those reported in other studies conducted on the industry level in suggesting that production technology responds endogenously to skill mix changes. As pointed out by Lewis (2012), such endogenous responses may importantly change the assessment of how immigration affects the labor market. Although we find evidence for aggregation error when performing analysis on the industry level, this error is relatively small. Our findings thus rule out that the previous industrylevel studies have severely underestimated between-firm adjustments and confirm the important role of within-firm adjustments in absorbing labor supply shocks. Our analysis further adds the insight that new and exiting firms play an important role in this adjustment process.

\section{Appendix A}

\section{Migration to Germany}

Table A1 provides an overview of the size and composition of the net foreign immigrant inflow into Germany between 1985 and $1995,{ }^{33}$ which comprises nearly 3 million new immigrants or a net inflow rate (relative to the 1985 West German population) of $5.0 \%$. Of these immigrants, more than a quarter originated from the former Yugoslavia as a result of the civil wars in the first half of the 1990s, followed by Asia (15.9\%),

${ }^{33}$ In addition to the significant inflow of foreign immigrants, a large group of ethnic German immigrants arrived in Germany over the 1990s. As these immigrants received German citizenship upon arrival and, for legal reasons, were limited in their choice of place of residence, we do not include them in the construction of our instrumental variable. For details, see Glitz (2012). 
Table A1

Summary Statistics of Immigrant Inflow, 1985-95

\begin{tabular}{lccccr}
\hline & $\begin{array}{c}\text { Immigrant } \\
\text { Inflow }\end{array}$ & $\begin{array}{c}\text { \% Share } \\
\text { of Inflow }\end{array}$ & $\begin{array}{c}\text { Low } \\
\text { Education }\end{array}$ & $\begin{array}{c}\text { Medium } \\
\text { Education }\end{array}$ & $\begin{array}{c}\text { High } \\
\text { Education }\end{array}$ \\
\hline Former Yugoslavia & 765,974 & 26.1 & 47.6 & 44.8 & 7.6 \\
Asia & 467,736 & 15.9 & 58.4 & 25.0 & 16.6 \\
Poland & 377,723 & 12.9 & 24.8 & 60.5 & 14.8 \\
Turkey & 321,242 & 11.0 & 78.4 & 16.8 & 4.9 \\
Former Soviet Union & 243,767 & 8.3 & 31.0 & 38.0 & 31.1 \\
Western Europe & 162,030 & 5.5 & 27.0 & 42.4 & 30.6 \\
Africa & 152,250 & 5.2 & 69.4 & 22.0 & 8.7 \\
Romania & 147,020 & 5.0 & 41.3 & 41.1 & 17.5 \\
Centraland Eastern Europe & 107,677 & 3.7 & 35.3 & 47.7 & 17.0 \\
Greece & 68,505 & 2.3 & 68.2 & 27.9 & 3.8 \\
Portugal & 51,175 & 1.7 & 73.3 & 22.1 & 4.5 \\
Italy & 36,941 & 1.3 & 65.3 & 24.6 & 10.1 \\
Central and South America & 36,778 & 1.3 & 34.8 & 32.3 & 32.9 \\
North America & 7,712 & .3 & 32.5 & 15.1 & 52.4 \\
Others & $-13,045$ & -.4 & 39.5 & 27.7 & 32.8 \\
\cline { 2 - 3 } All & $2,933,485$ & 100.0 & 48.6 & 37.4 & 14.0 \\
\hline
\end{tabular}

SOURCES.- Statistical Office and German Microcensus.

NOTE.-Immigrant inflow refers to the net overall inflow between 1985 and 1995 . The skill distribution refers to the educational attainment of immigrants aged 15-64 at the time of entry, calculated using available information from the German Microcensus that is closest to the actual year of arrival. Individuals with a low educational level are those without postsecondary education, those with a medium educational level have obtained postsecondary vocational or apprenticeship degrees, and those with a high educational level have attended college.

Poland (12.9\%), and Turkey (11.0\%). There is, however, substantial variation in the immigrant inflows across labor market regions, varying between $-0.6 \%$ (Rhein-Hunsrück-Kreis) and $8.9 \%$ (Krefeld), with a standard deviation of $1.7 \%$. Overall, the newly arriving immigrants were relatively low skilled compared to the native German population in 1995: $48.6 \%$ had low educational attainment, compared to $25.2 \%$ of the German population. ${ }^{34}$ However, as shown in table A1, there is substantial variation across countries of origin.

\section{Appendix B \\ Decompositions}

\section{Basic Decomposition}

The change in skill-specific employment in production unit $j$ in a local labor market is given by:

${ }^{34}$ The remaining shares for the native German population are $64.4 \%$ with medium and $1.4 \%$ with high educational levels. All figures are based on the German Microcensus 1995. 


$$
\Delta X_{i}=\Delta N_{i}=\sum_{j} \Delta N_{i j}
$$

Dividing by the total employment of skill group $i$ in the base period (denoted by subscript 0 ) and then expanding gives

$$
\frac{\Delta X_{i}}{X_{i 0}}=\frac{\Delta N_{i}}{N_{i 0}}=\sum_{j} \frac{\Delta N_{i j}}{N_{i 0}}=\sum_{j} \frac{N_{i j o}}{N_{i 0}} \frac{\Delta N_{i j}}{N_{i j 0}}=\sum_{j} s_{i j 0} \% \Delta N_{i j} .
$$

Letting $M_{j}$ be a measure of the size of production unit $j$, we can then decompose the term $\% \Delta N_{i j}$ into three terms:

$$
\begin{aligned}
& \% \Delta N_{i j}=\frac{\Delta N_{i j}}{N_{i j 0}}=\frac{M_{j} N_{i j}}{N_{i j 0} M_{j}}-\frac{M_{j_{0}} N_{i j_{0}}}{N_{i j_{0}} M_{j 0}}=\frac{M_{j} N_{i j}}{N_{i j 0} M_{j}}-1 \\
& =\frac{N_{i j} M_{j_{0}}}{M_{j} N_{i j o}}+\frac{\left(M_{j}-M_{j_{0}}\right) N_{i j}}{M_{j} N_{i j o}}-1 \\
& =\frac{M_{j}-M_{j_{0}}}{M_{j_{0}}}+\frac{N_{i j} M_{j 0}}{M_{j} N_{i j 0}}-1+\frac{M_{j}-M_{j 0}}{M_{j_{0}}}\left(\frac{N_{i j} M_{j 0}}{M_{j} N_{i j 0}}-1\right) \\
& =\left(\frac{M_{j}-M_{j_{0}}}{M_{j_{0}}}\right)+\left(\frac{\frac{N_{i j}}{M_{j}}-\frac{N_{i j_{0}}}{M_{j_{0}}}}{\frac{N_{i j_{0}}}{M_{j_{0}}}}\right)+\left(\frac{M_{j}-M_{j_{0}}}{M_{j 0}}\right)\left(\frac{\frac{N_{i j}}{M_{j}}-\frac{N_{i j_{0}}}{M_{j_{0}}}}{\frac{N_{i j_{0}}}{M_{j_{0}}}}\right) \\
& =\% \Delta M_{j}+\% \Delta\left(\frac{N_{i j}}{M_{j}}\right)+\% \Delta M_{j} \times \% \Delta\left(\frac{N_{i j}}{M_{j}}\right),
\end{aligned}
$$

which, by substitution into equation (B1), yields the decomposition given in equation (1).

\section{Firm-Level Decomposition}

Distinguishing individual firms $f$ and allowing for their entry and exit, the change in skill-specific employment in all tradable industries $j$ in a local labor market is given by:

$$
\begin{aligned}
\Delta N_{i} & =\sum_{j} \Delta N_{i j} \\
& =\sum_{j}\left(\sum_{f \in \mathcal{X}_{j}^{p}} \Delta N_{i j f}+\sum_{f \in \mathcal{X}_{j}^{n}} \Delta N_{i j f}+\sum_{f \in \mathcal{X}_{j}^{o}} \Delta N_{i j f}\right) .
\end{aligned}
$$

Dividing by the total employment of skill group $i$ in the base period (denoted by subscript 0 ) and then expanding gives 


$$
\begin{aligned}
\frac{\Delta N_{i}}{N_{i_{0}}} & =\sum_{j}\left(\sum_{f \in \mathcal{X}_{j}^{p}} \frac{\Delta N_{i j f}}{N_{i_{0}}}+\sum_{f \in \mathcal{X}_{j}^{n}} \frac{\Delta N_{i j f}}{N_{i_{0}}}+\sum_{f \in \mathcal{X}_{j}^{o}} \frac{\Delta N_{i j f}}{N_{i_{0}}}\right) \\
& =\sum_{j} \sum_{f \in \mathcal{X}_{j}^{p}} \frac{N_{i j f_{0}}}{N_{i_{0}}} \frac{\Delta N_{i j f}}{N_{i j f_{0}}}+\sum_{j} \sum_{f \in \mathcal{X}_{j}^{n}} \frac{\Delta N_{i j f}}{N_{i_{0}}}+\sum_{j} \sum_{f \in \mathcal{X}_{j}^{o}} \frac{N_{i j f_{0}}}{N_{i_{0}}} \frac{\Delta N_{i j f}}{N_{i j f_{0}}} \\
& =\sum_{j} \sum_{f \in \mathcal{X}_{j}^{p}} s_{i j f_{0}} \% \Delta N_{i j f}+\sum_{j} \sum_{f \in \mathcal{X}_{j}^{n}} \frac{N_{i j f}}{N_{i_{0}}}-\sum_{j} \sum_{f \in \mathcal{X}_{j}^{o}} \frac{N_{i j f_{0}}}{N_{i_{0}}}
\end{aligned}
$$

where $s_{i j f_{0}}=\left(N_{i j f_{0}} / N_{i 0}\right)$. Letting $M_{j f}$ be a measure of firm size, we can write $\% \Delta N_{i f f}=\% \Delta M_{j f}+\% \Delta\left(N_{i j f} / M_{j f}\right)+\% \Delta M_{j f} \times \% \Delta\left(N_{i j f} / M_{i f}\right)$ (compare App. B, Sec. B1), which by substitution into equation (B2) yields the firmlevel decomposition given in equation (3).

\section{New/Old Firm Decomposition}

The terms involving new and old firms can be decomposed as follows:

$$
\begin{aligned}
& \sum_{j} \sum_{f \in \mathcal{X}_{j}^{n}} \frac{N_{i j f}}{N_{i_{0}}}=\sum_{t=1}^{T} \sum_{j} \sum_{f \in \mathcal{X}_{j t}^{n}} \frac{N_{i j f_{t}}}{N_{i_{0}}}+\sum_{t=1}^{T} \sum_{j} \sum_{f \in \mathcal{X}_{j t}^{n}} \frac{\Delta_{t}^{T} N_{i j f_{t}}}{N_{i_{0}}} \\
& =\sum_{t=1}^{T}\left(\sum_{j} \sum_{f \in \mathcal{X}_{j t}^{n}}\left(\frac{N_{i j_{t}}}{N_{i_{0}}}\right)\left(\frac{M_{i f_{t}}}{M_{j_{t}}}\right)+\sum_{j} \sum_{f \in \mathcal{X}_{j t}^{n}}\left(\frac{N_{i j_{t}}}{N_{i_{0}}}\right)\left(\frac{M_{i f_{t}}}{M_{j_{t}}}\right)\left(\frac{\frac{N_{i j f_{t}}}{M_{i f_{t}}}-\frac{N_{i j_{t}}}{M_{j t}}}{\frac{N_{i j_{t}}}{M_{j_{t}}}}\right)\right) \\
& +\sum_{t=1}^{T}\left(\sum_{j} \sum_{f \in \mathcal{X}_{j t}^{n}} \frac{N_{i j f_{t}}}{N_{i_{0}}} \frac{\Delta_{t}^{T} N_{i j f_{t}}}{N_{i j f_{t}}}\right) \\
& =\underbrace{\sum_{t=1}^{T} \sum_{j} \sum_{f \in \mathcal{X}_{j t}^{n}}\left(\frac{N_{i j_{t}}}{N_{i_{0}}}\right)\left(\frac{M_{i f_{t}}}{M_{j_{t}}}\right)}_{\text {new firm entry scale }}+\underbrace{\sum_{t=1}^{T} \sum_{j} \sum_{f \in \mathcal{X}_{j t}^{n}}\left(\frac{N_{i j_{t}}}{N_{i_{0}}}\right)\left(\frac{M_{i f_{t}}}{M_{j_{t}}}\right)\left(\frac{\frac{N_{i f_{t}}}{M_{i f_{t}}}-\frac{N_{i j_{t}}}{M_{j_{t}}}}{\frac{N_{i j_{t}}}{M_{j_{t}}}}\right)}_{\text {new firm entry intensity }} \\
& +\underbrace{\sum_{t=1}^{T} \sum_{j} \sum_{f \in \mathcal{X}_{j t}^{n}} \frac{N_{i j f_{t}}}{N_{i_{0}}} \% \Delta_{t}^{T} M_{j f_{t}}}_{\text {new firm growth scale }}+\underbrace{\sum_{t=1}^{T} \sum_{j} \sum_{f \in \mathcal{X}_{j t}^{n}} \frac{N_{i j f_{t}}}{N_{i_{0}}} \% \Delta_{t}^{T}\left(\frac{N_{i j f_{t}}}{M_{j f_{t}}}\right)}_{\text {new firm growth intensity }} \\
& +\underbrace{\sum_{t=1}^{T} \sum_{j} \sum_{f \in \mathcal{X}_{j t}^{n}} \frac{N_{i f_{t}}}{N_{i_{0}}} \% \Delta_{t}^{T} M_{j f_{t}} \% \Delta_{t}^{T}\left(\frac{N_{i j f_{t}}}{M_{j f_{t}}}\right)}_{\text {new firm growth residual }}
\end{aligned}
$$




$$
\begin{aligned}
& \sum_{j} \sum_{f \in \mathcal{X}_{j}^{o}} \frac{N_{i f_{0}}}{N_{i_{0}}}=\sum_{t=0}^{T-1} \sum_{j} \sum_{f \in \mathcal{X}_{j t}^{o}} \frac{N_{i j f_{t}}}{N_{i_{0}}}-\sum_{t=0}^{T-1} \sum_{j} \sum_{f \in \mathcal{X}_{j t}^{o}} \frac{\Delta_{0}^{t} N_{i j f_{t}}}{N_{i_{0}}} \\
& =\sum_{t=0}^{T-1}\left(\sum_{j} \sum_{f \in \mathcal{X}_{j t}^{o}}\left(\frac{N_{i j_{t}}}{N_{i_{0}}}\right)\left(\frac{M_{i f_{t}}}{M_{j_{t}}}\right)+\sum_{j} \sum_{f \in \mathcal{X}_{j t}^{o}}\left(\frac{N_{i j_{t}}}{N_{i_{0}}}\right)\left(\frac{M_{i f_{t}}}{M_{j_{t}}}\right)\left(\frac{\frac{N_{i j f_{t}}}{M_{j f_{t}}}-\frac{N_{i j_{t}}}{M_{j t}}}{\frac{N_{i j_{t}}}{M_{j t}}}\right)\right) \\
& -\sum_{t=0}^{T-1}\left(\sum_{j} \sum_{f \in \mathcal{X}_{i t}^{o}} \frac{N_{i j f_{0}}}{N_{i_{0}}} \frac{\Delta_{0}^{t} N_{i j f_{t}}}{N_{i j f_{0}}}\right) \\
& =\underbrace{\sum_{t=0}^{T-1} \sum_{j} \sum_{f \in \mathcal{X}_{j t}^{o}}\left(\frac{N_{i j_{t}}}{N_{i_{0}}}\right)\left(\frac{M_{j f_{t}}}{M_{j_{t}}}\right)}_{\text {old firm exit scale }}+\underbrace{\sum_{t=0}^{T-1} \sum_{j} \sum_{f \in \mathcal{X}_{j t}^{o}}\left(\frac{N_{i j_{t}}}{N_{i_{0}}}\right)\left(\frac{M_{j f_{t}}}{M_{j_{t}}}\right)\left(\begin{array}{l}
\frac{N_{i j f_{t}}}{M_{j f_{t}}}-\frac{N_{i j_{t}}}{M_{j t}} \\
\frac{N_{i j_{t}}}{M_{j_{t}}}
\end{array}\right)}_{\text {old firm exit intensity }} \\
& -\underbrace{\sum_{t=0}^{T-1} \sum_{j} \sum_{f \in \mathcal{X}_{j t}^{o}} \frac{N_{i j f_{0}}}{N_{i_{0}}} \% \Delta_{0}^{t} M_{j f_{t}}}_{\text {old firm growth scale }}-\underbrace{\sum_{t=0}^{T-1} \sum_{j} \sum_{f \in \mathcal{X}_{j t}^{o}} \frac{N_{i j f_{0}}}{N_{i_{0}}} \% \Delta_{0}^{t}\left(\frac{N_{i j f_{t}}}{M_{j f_{t}}}\right)}_{\text {old firm growth intensity }} \\
& -\underbrace{\sum_{t=0}^{T-1} \sum_{j} \sum_{f \in \mathcal{X}_{j t}^{o}} \frac{N_{i j f_{0}}}{N_{i_{0}}} \% \Delta_{0}^{t} M_{j f_{t}} \% \Delta_{0}^{t}\left(\frac{N_{i j f_{t}}}{M_{j f_{t}}}\right)}_{\text {old firm growth residual }} .
\end{aligned}
$$




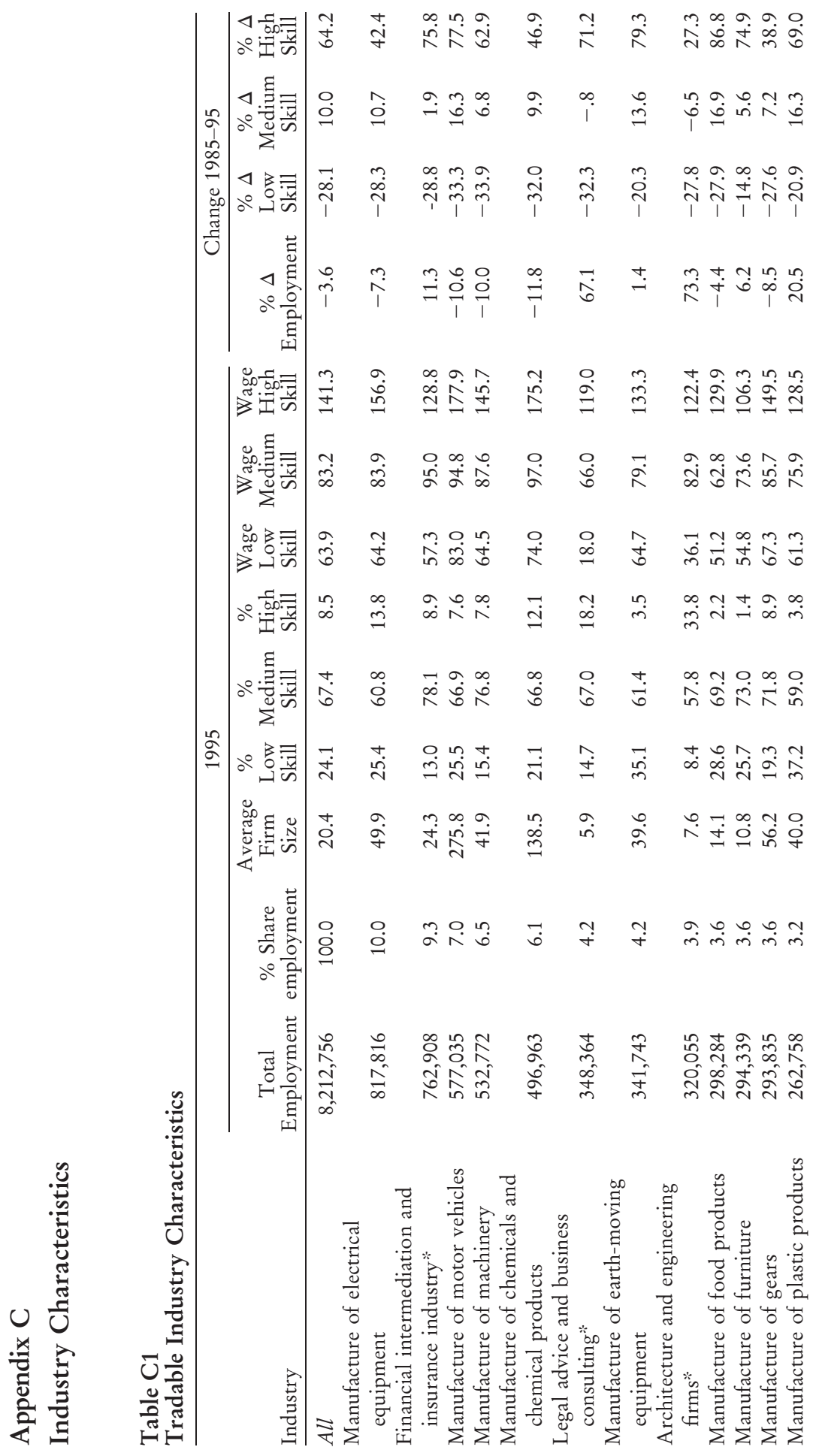

This content downloaded from 128.041.061.054 on December 20, 2017 11:21:11 AM All use subject to University of Chicago Press Terms and Conditions (http://www.journals.uchicago.edu/t-and-c). 


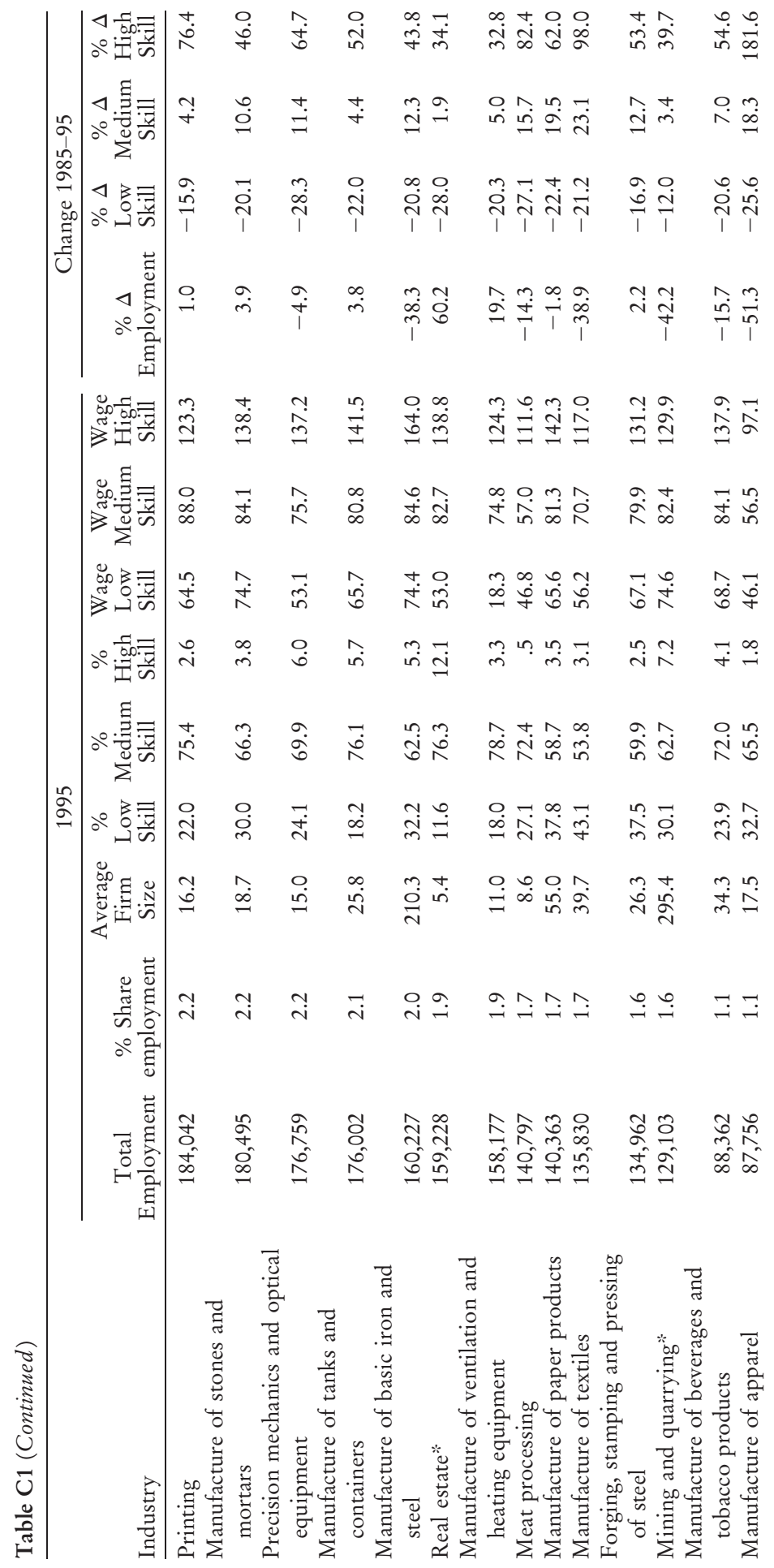

This content downloaded from 128.041.061.054 on December 20, 2017 11:21:11 AM All use subject to University of Chicago Press Terms and Conditions (http://www.journals.uchicago.edu/t-and-c). 


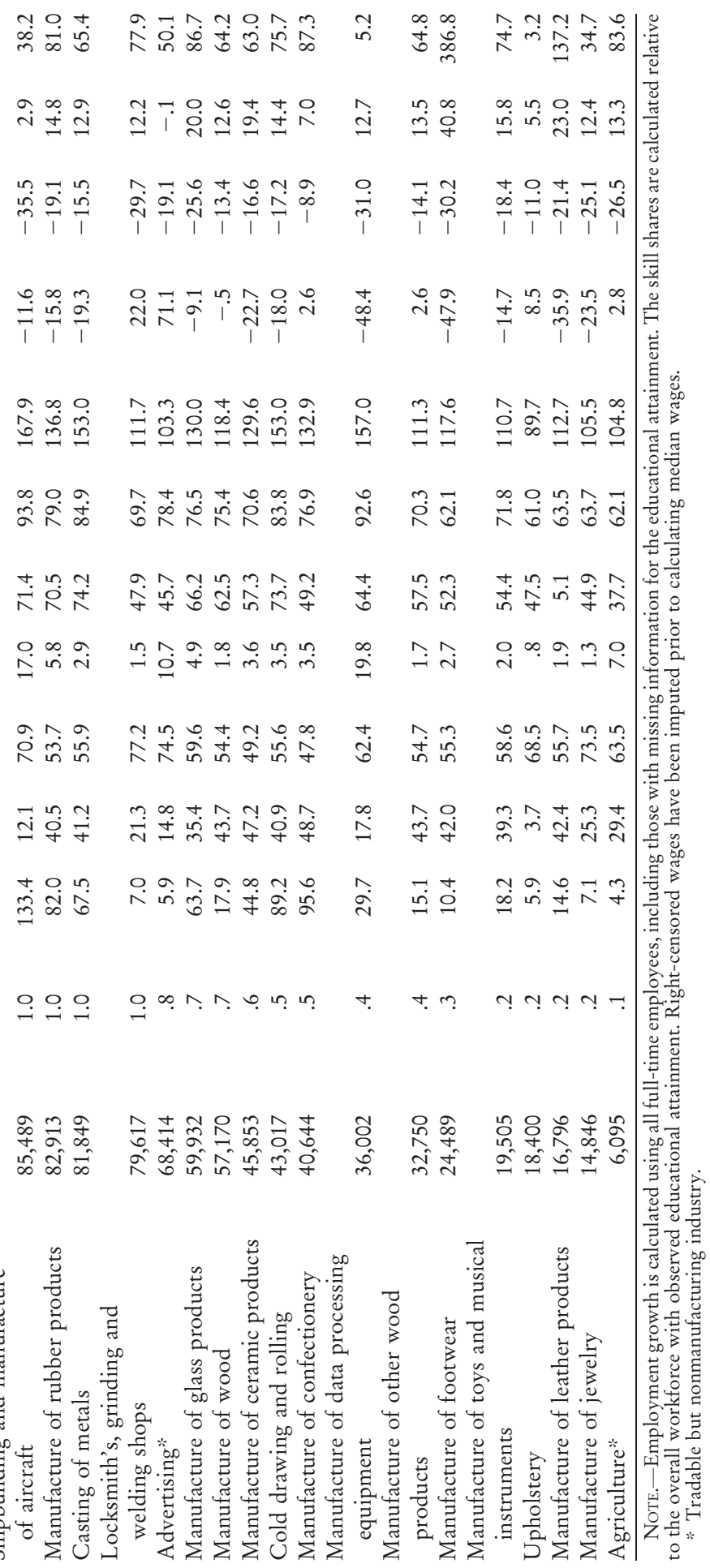




\section{Appendix D}

\section{The First Stage}

In figure D1, we show the relation between our instrument (described in Sec. II.A) and local labor supply changes, both overall and separately by skill group, by plotting the percentage change in local labor supply against the predicted inflow of immigrants and the corresponding (weighted) regression line, after previously netting out region and education group fixed effects. All regressions are based on the weights for the tradable sector. As the figures show, there is a strong positive relationship between the changes in labor supply and the predicted immigrant inflow rates for the low and medium skill groups, with a slope coefficient of .407 and .410 , respectively, and a somewhat weaker relationship for the high skill group, with a slope coefficient of .18. Overall, the first-stage relation between our instrument and the change in local labor supply for the pooled sample of all three skill groups is strong, with a slope parameter of .297 and a standard error of .058, yielding a first-stage $F$-statistic of 26.0 . 


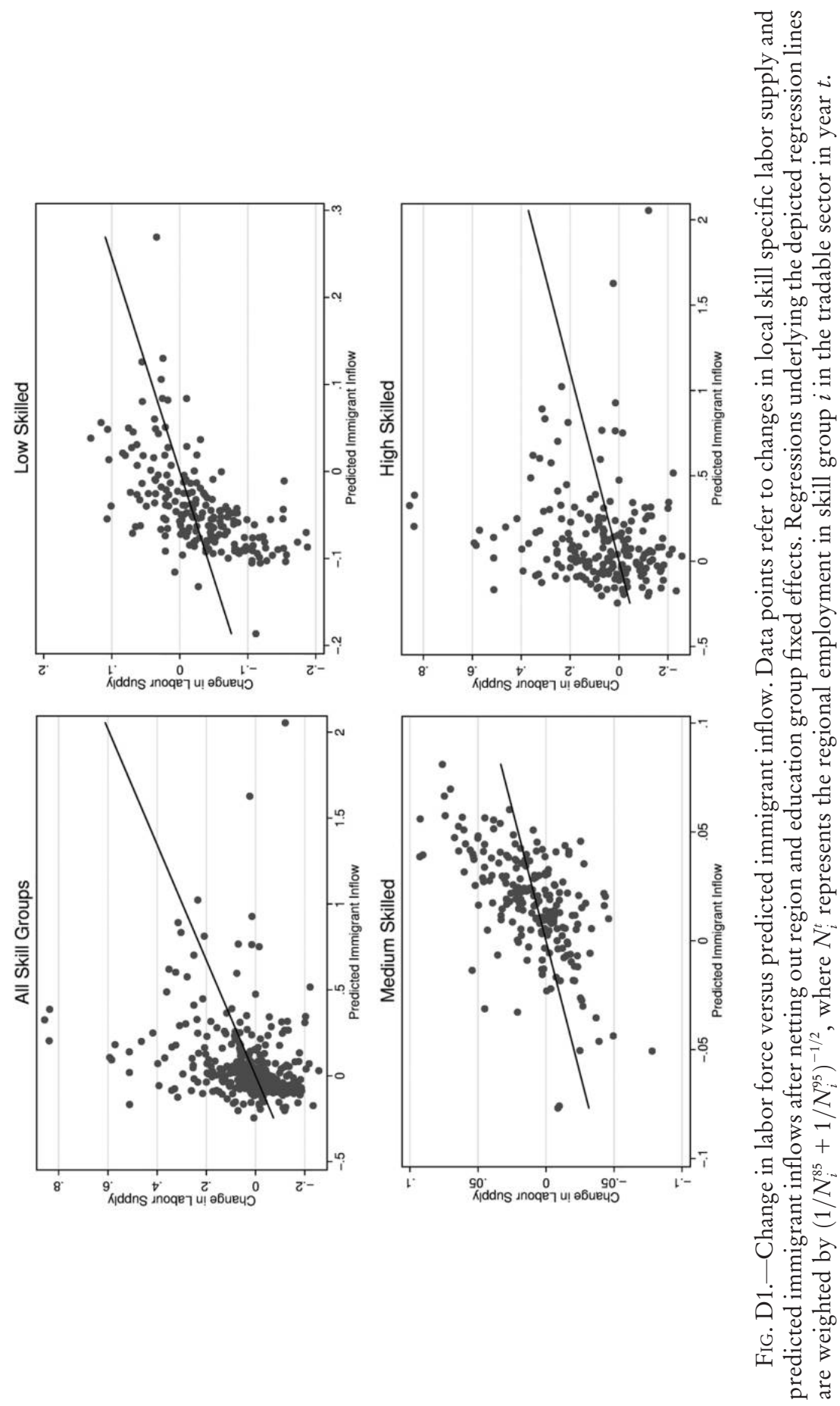

This content downloaded from 128.041.061.054 on December 20, 2017 11:21:11 AM 


\section{References}

Acemoglu, Daron. 1998. Why do new technologies complement skills? Directed technical change and wage inequality. Ouarterly Iournal of Economics 113, no. 4:1055-89.

. 2002. Technical change, inequality, and the labor market. Lournal of Economic Literature 40, no. 1:7-72.

Altonji, Joseph G., and David Card. 1991. The effects of immigration on the labor market outcomes of less-skilled natives. In Immigration, trade, and the labor market, ed. John M. Abowd and Richard B. Freeman. Chicago: University of Chicago Press.

Antonczyk, Dirk, Bernd Fitzenberger, and Katrin Sommerfeld. 201. Rising wage inequality, the decline of collective bargaining, and the gender wage gap. Labour Economics 17, no. 5:835-47.

Autor, David H., Lawrence F. Katz, and Alan B. Krueger. 1998. Computing inequality: Have computers changed the labor market? Ouarterly Lournal of Economics 113, no. 4:1169-1213.

Bartel, Ann P. 1989. Where do the new US immigrants live? Iournal of Labor Economics 7, no. 4:371-91.

Beaudry, Paul, Mark Doms, and Ethan G. Lewis. 2010. Should the personal computer be considered a technological revolution? Evidence from US metropolitan areas. Lournal of Political Economy 118, no. 5:988-1036.

Beaudry, Paul, and David A. Green. 2003. Wages and employment in the United States and Germany: What explains the differences? American Economic Review 93, no. 3:573-602.

. 2005. Changes in US wages, 1976-2000: Ongoing skill bias or major technological change? Iournal of Labor Economics 23, no. 3:609-48.

Beaudry, Paul, David A. Green, and Ben Sand. 2013. How elastic is the job creation curve? Working paper, University of British Columbia.

Bernard, Andrew B., and J. Bradford Jensen. 1997. Exporters, skill upgrading, and the wage gap. Iournal of International Economics 42, nos. 1-2:3-31.

Borjas, George J. 2003. The labor demand curve is downward sloping: Reexamining the impact of immigration on the labor market. Ouarterly Lournal of Economics 118, no. 4:1335-74.

Broda, Christian, and David E. Weinstein. 2006. Globalization and the gains from variety. Ouarterly Iournal of Economics 121, no. 2:541-85.

Bundesagentur für Arbeit. 2004. Arbeitsmarkt 2003. Amtliche Nachrichten der Bundesagentur für Arbeit.

Card, David. 2001. Immigrant inflows, native outflows, and the local labor market impacts of higher immigration. Lournal of Labor Economics 19, no. 1:22-64.

Card, David, and Ethan G. Lewis. 2007. The diffusion of Mexican immigrants during the 1990s: Explanations and impacts. In Mexican im- 
migration to the United States, ed. George J. Borjas. Chicago: University of Chicago Press.

Caselli, Francesco, and Wilbur John Coleman. 2006. The world technology frontier. American Economic Review 96, no. 3:499-522.

Ciccone, Antonio, and Giovanni Peri. 2011. Schooling supply and the structure of production: Evidence from US states, 1950-1990. NBER Working Paper no. 17683, National Bureau of Economic Research, Cambridge, MA. Dunne, Timothy, Mark J. Roberts, and Larry Samuelson. 1989a. The growth and failure of U.S. manufacturing plants. Ouarterly Iournal of Economics 104, no. 4:671-98.

1989b. Plant turnover and gross employment flows in the US manufacturing sector. Lournal of Labor Economics 7, no. 1:48-71.

Dustmann, Christian, Francesca Fabbri, and Ian Preston. 2005. The impact of immigration on the British labour market. Economic Iournal 115, no. 507:F324-F341.

Dustmann, Christian, Tommaso Frattini, and Ian Preston. 2013. The effect of immigration along the distribution of wages. Review of Economic Studies 80, no. 1:145-73.

Dustmann, Christian, Johannes Ludsteck, and Uta Schönberg. 2009. Revisiting the German wage structure. Ouarterly Journal of Economics 124, no. 2:843-81.

Dustmann, Christian, and Uta Schönberg. 2012. What makes firm-based vocational training schemes successful? The role of commitment. American Economic Journal: Applied Economics 4, no. 2:36-61.

Ethier, Wilfred J. 1972. Nontraded goods and the Heckscher-Ohlin model. International Economic Review 13, no. 1:132-47. of Economics 99, no. 1:193-20.

Fischer, Gabriele, Florian Janik, Dana Müller, and Alexandra Schmucker. 2008. The IAB establishment panel from sample to survey to projection. FDZ Methodenreport no. 01/2008, Institut für Arbeitsmarkt-und Berufsforschung (Institute for Employment Research; IAB), Nuremberg, Germany.

Gandal, Neil, Gordon H. Hanson, and Matthew J. Slaughter. 2004. Technology, trade, and adjustment to immigration in Israel. European Economic Review 48, no. 2:403-28.

Gartner, Hermann. 2004. Die Imputation von Lhnen oberhalb der Beitragsbemessungsgrenze in der IAB-Beschäftigtenstatistik. IAB Working Paper, Institut für Arbeitsmarkt-und Berufsforschung (Institute for Employment Research; IAB), Nuremberg, Germany.

Gaston, Noel, and Douglas Nelson. 200. Immigration and labour-market outcomes in the United States: A political-economy puzzle. Oxford Review of Economic Policy 16, no. 3:104-14. 
Glitz, Albrecht. 2012. The labor market impact of immigration: A quasiexperiment exploiting immigrant location rules in Germany. Lournal of Labor Economics 30, no. 1:175-213.

González, Libertad, and Francesc Ortega. 2011. How do very open economies absorb large immigration flows? Recent evidence from Spanish regions. Labour Economics 18, no. 1:57-70.

Hanson, Gordon H., and Matthew J. Slaughter. 2002. Labor-market adjustment in open economies: Evidence from US states. Iournal of International Economics 57, no. 1:3-29.

Jaeger, David A. 2007. Green cards and the location choices of immigrants in the United States, 1971-200. Research in Labor Economics 27:131-83.

Komiya, Ryutaro. 1967. Non-traded goods and the pure theory of international trade. International Economic Review 8, no. 2:132-52.

Leamer, Edward E., and James Levinsohn. 1995. International trade theory: The evidence. In Handbook of international economics, vol. 3, ed. Gene M. Grossman and Kenneth Rogoff. Amsterdam: Elsevier.

Lewis, Ethan G. 2003. Local open economies within the U.S.: How do industries respond to immigration? Working Paper no. 04-1, Federal Reserve Bank of Philadelphia.

- 2011. Immigration, skill mix, and capital-skill complementarity. Ouarterly Iournal of Economics 126, no. 2:1029-69.

. 2012. Immigration and production technology. NBER Working Paper no. 18310, National Bureau of Economic Research, Cambridge, MA.

Manacorda, Marco, Alan Manning, and Jonathan Wadsworth. 2012. The impact of immigration on the structure of wages: Theory and evidence from Britain. Lournal of the European Economic Association 10, no. 1: 120-51.

Monras, Joan. 2011. The sluggish movement of workers: Rethinking immigration absorption, Rybczynski effects and wage responses. Unpublished manuscript, Sciences Po and LIEPP.

Okkerse, Liesbet. 2008. How to measure labour market effects of immigration: A review. Lournal of Economic Survevs 22, no. 1:1-3.

Olney, William W. 2013. Immigration and firm expansion. Lournal of Regional Science 53, no. 1:142-57.

Ottaviano, Gianmarco I. P., and Giovanni Peri. 2012. Rethinking the effect of immigration on wages. Lournal of the European Economic Association 10, no. 1:152-97.

Rybczynski, Tadeusz M. 1955. Factor endowments and relative commodity prices. Economica 22, no. 88:336-41.

Schott, Peter K. 2004. Across-product versus within-product specialization in international trade. Ouarterly Iournal of Economics 119, no. 2:647-78. 